University of Nebraska - Lincoln

DigitalCommons@University of Nebraska - Lincoln

6-2021

\title{
Spatiotemporal Analysis of Extreme Precipitation in the Missouri River Basin from 1950 to 2019
}

Paul Flanagan

Rezaul Mahmood

Follow this and additional works at: https://digitalcommons.unl.edu/natrespapers

Part of the Natural Resources and Conservation Commons, Natural Resources Management and Policy Commons, and the Other Environmental Sciences Commons

This Article is brought to you for free and open access by the Natural Resources, School of at DigitalCommons@University of Nebraska - Lincoln. It has been accepted for inclusion in Papers in Natural Resources by an authorized administrator of DigitalCommons@University of Nebraska - Lincoln. 


\title{
Spatiotemporal Analysis of Extreme Precipitation in the Missouri River Basin from 1950 to 2019
}

\author{
PAUl Flanagan $^{\mathrm{a}}$ AND ReZAul MAHMOOD ${ }^{\mathrm{b}, \mathrm{c}}$ \\ ${ }^{\text {a }}$ U.S. Department of Agriculture Agricultural Research Service, El Reno, Oklahoma \\ ${ }^{\mathrm{b}}$ High Plains Regional Climate Center, University of Nebraska-Lincoln, Lincoln, Nebraska \\ ${ }^{\mathrm{c}}$ School of Natural Resources, University of Nebraska-Lincoln, Lincoln, Nebraska
}

(Manuscript received 15 September 2020, in final form 20 April 2021)

\begin{abstract}
Extreme precipitation events are challenging to local and regional stakeholders across the United States. The Missouri River basin (MoRB), covering an area over 1.29 million $\mathrm{km}^{2}$, is prone to extreme precipitation events. These events are exacerbated by the complex terrain in the west and the numerous weather and climate features that impact the region on a seasonal and annual basis (low-level jets, mesoscale convective systems, extreme cold air intrusions, etc.). Without an in-depth analysis of extreme precipitation in the MoRB, the evolving nature of extreme precipitation is not known. This situation warrants an analysis of extreme precipitation, especially relating to subannual variations when extreme precipitation is more impactful. To this end, data from 131 U.S. Historical Climatology Network (USHCN) stations were used to determine the nature of extreme precipitation from 1950 to 2019. Annual 99th-percentile events and annual station maximum precipitation events occur more frequently in the eastern MoRB than in the western MoRB, in line with the annual precipitation climatology. Results show that 99th-percentile events and annual station maximum precipitation events are becoming more frequent across the MoRB. Through analysis of 3-month extreme precipitation trends, areas in the eastern and southern MoRB are shown to have an increase in event frequency and intensity. Frequency shifts in the 99th-percentile events, however, have occurred across the entire region. The increasing frequency of extreme events in the western MoRB represents a significant change for the hydroclimate of the region. Overall, the results from this work show that MORB extreme precipitation has increased in frequency and intensity during the 1950-2019 period.
\end{abstract}

KEYWORDS: North America; Extreme events; Precipitation; Climate variability; Trends

\section{Introduction}

Extreme precipitation events within the Missouri River basin (MoRB) have widely varying impacts. These include, for example, major river floods, flash floods, agricultural field flooding, dangerous ice flows, and large-scale infrastructure loss or damage. Such an event during March 2019 (Flanagan et al. 2020) caused an estimated $\$ 2.9$ billion in direct damages with around 20 million acres $(1$ acre $=0.4$ ha) of agricultural land left fallow because of remaining flood waters (USDA 2019). Flash flooding can also be an issue in the region. For example, in early June 1972, over $786 \mathrm{~mm}$ of rain fell in a 6-h period in the eastern Black Hills and $254 \mathrm{~mm}$ for that same period over a $60-\mathrm{mi}(97 \mathrm{~km})$ area in South Dakota leading to the highest floods recorded in the state. This event resulted in 237 deaths and 3057 injuries and caused over \$160 million in damages (USGS and NOAA 1972). During another event, occurred in Kansas City on 12-13 September 1977, nearly $406 \mathrm{~mm}$ of rainfall was recorded that led to 25 deaths and over $\$ 50$ million in damages (USGS and NOAA 1977). While typically caused by large-scale flooding, damage to agricultural fields and crops can occur from localized extreme precipitation events leading to soil damage (Kozdrój and van Elsas 2000), increased possibility of plant disease (Ashraf and Habib-urRehman 1999), and delayed planting as a result of farmers' inability to operate machinery in the wet soil (Rosenzweig et al. 2002). Moreover, large-scale floods can lead to widespread and long-lasting impacts resulting in increased food

Corresponding author: Paul Flanagan, paul.flanagan2@usda.gov prices around the country and devastate local economies reliant on agricultural production (Downton et al. 2005; Xiao et al. 2013; Mallakpour and Villarini 2015).

The Missouri River is the longest river in the United States, and the MoRB watershed stretches over 1.29 million $\mathrm{km}^{2}$ (U.S. Department of the Interior Bureau of Reclamation 2016). Because of its size, the MoRB experiences a number of different hydroclimatic conditions. The western MoRB states, including Montana, Wyoming, and Colorado, observe lower precipitation totals throughout a calendar year (Fig. 1) with heavy snowfall events across the mountains providing most of the water for the region (Najibi et al. 2017; Wise et al. 2018). The eastern MoRB states, including North Dakota, South Dakota, Nebraska, Kansas, Iowa, and Missouri, observe higher amounts of precipitation (Fig. 1) and less snowfall relative to the mountainous regions in the west (Najibi et al. 2017; Wise et al. 2018). As most of the precipitation in the eastern MoRB states occurs during the spring and summer, the hydrologic system of the eastern states is dependent on the water recharge from the region's snowfall and the snowmelt of the mountainous region to the west (Qiao et al. 2014; Barnhart et al. 2016; Wise et al. 2018). Thus, the thawing months of the year are highly susceptible to floods, as excessive snowfall, higher river levels, excessive river ice, and/or an extreme rainfall event can quickly overwhelm the MoRB hydrological systems during the late winter and early spring season (Najibi et al. 2017; Flanagan et al. 2020). This can be compounded by the colder temperatures of the winter season (Flanagan et al. 2017), which leads to increased runoff of any liquid precipitation due to frozen soils (Cherkauer and Lettenmaier 1999; Niu and Yang 2006). 


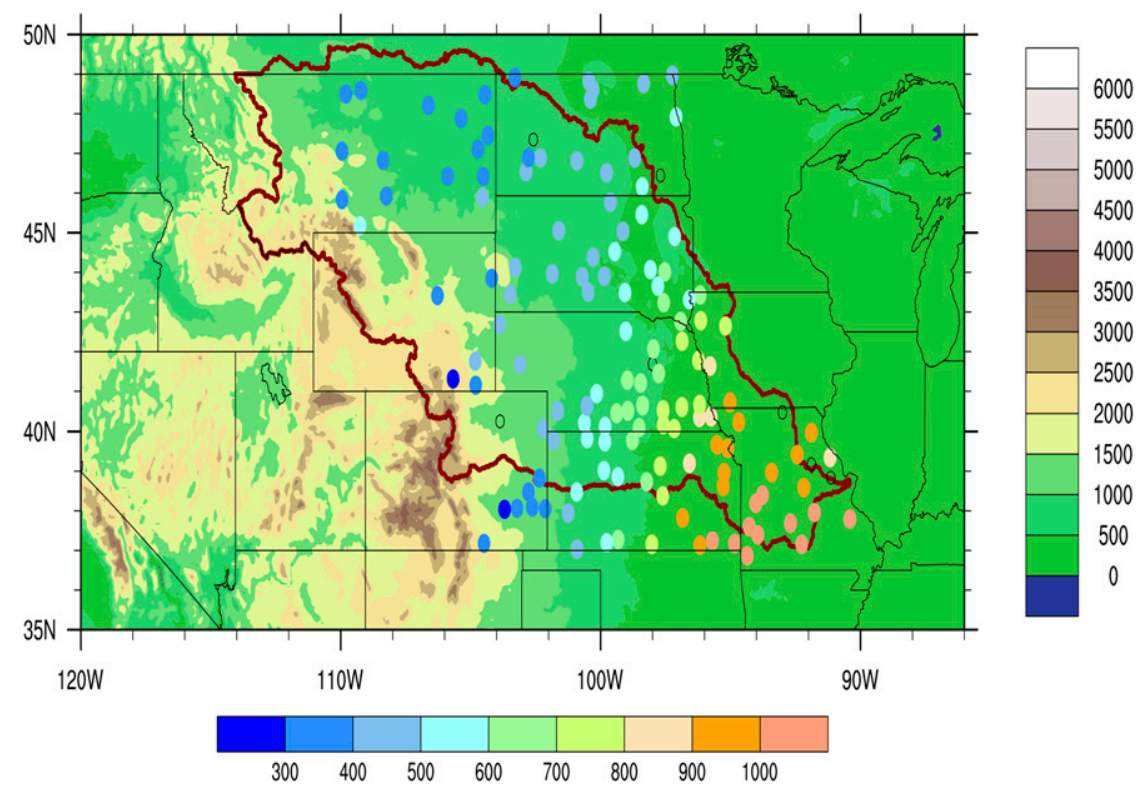

FIG. 1. Map of the study area. The Missouri River Basin area is outlined with a thick dark-red line. The color-filled circles represent stations used within the study, and the open circles represent stations that were excluded by the $10 \%$-or-less-missing-data filter. The map color fill is terrain height in meters. The color fill in each circle is the annual precipitation climatology $(\mathrm{mm})$ for the USHCN stations over the MoRB.

Precipitation in the north-central United States, or the MoRB as shown in Fig. 1, is driven by a number of different mechanisms on the climate and synoptic (temporal and spatial) scales. On the synoptic scale, precipitation is largely forced by processes such as the warm-season low-level jet (LLJ; Wallace 1975; Monaghan et al. 2010), potential vorticity anomalies (e.g., Appenzeller and Davies 1992; Moore et al. 2019), synoptic wave activity (Zhao et al. 2017; Flanagan et al. 2017), to name a few. Anomalies in such features [Great Plains LLJ (GPLLJ), anomalous wave activity, etc.] can modify precipitation or the drivers of precipitation to enhance the resultant precipitation amounts. Owing to the land-locked nature of the MoRB as it sits between the Rocky Mountain range to the west and the Mississippi River basin to the east, moisture for precipitation is typically drawn from the south, or the Gulf of Mexico (Higgins et al. 1997; Gimeno et al. 2010, 2013). This moisture transport is climatologically driven by the GPLLJ during the warm season and synoptic-scale weather systems throughout the year. Thus, precipitation and precipitation extremes in the MoRB is directly linked to the strength of the southerly flow produced by dynamic weather systems (potential vorticity and wave-activity anomalies included) and the GPLLJ (during the warm season).

Locally, land-use land-cover features have been shown to modify (DeAngelis et al. 2010) localized precipitation events. A large feature of climate change, land-use land-cover change (LULCC), has drastically altered the landscape of the central United States including the MoRB (DeAngelis et al. 2010; Ahiablame et al. 2017). Predominantly, this has taken the shape of changes from natural grassland or forest to agricultural land in the MoRB region. The impact of such a LULCC on the atmosphere is to increase low-level humidity through enhanced evapotranspiration during the late spring, summer, and early autumn seasons. Thus, LULC and LULCC can amplify or weaken precipitation events through the modification of the localized low-level moisture field.

Climate-scale drivers of precipitation for the central United States are predominantly from the Pacific Ocean basin, namely the Pacific decadal oscillation, El Niño-Southern Oscillation (ENSO), and Pacific-North American (PNA) pattern (RuizBarradas and Nigam 2005; Hu and Huang 2009; Mei and Wang 2011; Wise et al. 2018). Although climate-scale drivers typically impact weather at seasonal, annual, or longer time scales, they can still influence extreme precipitation on shorter temporal scales, such as through the PNA (Wise et al. 2018). Moreover, Wise et al. (2018) noted that the primary control on MoRB streamflow from teleconnections (PNA and ENSO in their study) is through the upper MoRB wintertime precipitation (snow in the higher elevations). Thus, precipitation and its extremes are forced by a large array of different features on a variety of temporal and spatial scales.

As a result of the high impact of extreme precipitation events, temporal and spatial changes owing to climate change or LULCC are especially important in the MoRB. Across the United States, total precipitation has increased by about $6 \%$ in the twentieth century (Karl et al. 2009; NCDC 2020; Groisman et al. 2012; Easterling et al. 2017). This change in precipitation is not spatially or temporally homogenous, as the amounts and extremes differ among regions (Kunkel et al. 1999; Kunkel 2003; DeGaetano 2009; Pryor et al. 2009; Groisman et al. 2012; Janssen et al. 2014; Yu et al. 2016; Easterling et al. 2017). Precipitation intensity and magnitude has been changing 
across the central United States, as small-scale heavy precipitation events have become more frequent and lighter precipitation events did not proportionately increase (Karl and Knight 1998; Groisman et al. 2004, 2005, 2012; Feng et al. 2016; Easterling et al. 2017). Because the geographic extent of these storms is smaller, they cause an increase in the variability of water resources in the region (Christian et al. 2015; Weaver et al. 2016; Flanagan et al. 2017, 2018).

Increases in the magnitude and frequency of extreme precipitation events could alter the threshold of an extreme event. As the magnitude of these extreme events increases, the thresholds used to define extreme events (typically percentile based) also change. Thus, events that were previously considered extreme (i.e., rare events) could be identified as "normal" or more frequent. This shift of extreme precipitation can be found in several regions in the United States, such as the Northeast (Karl and Knight 1998; Kunkel 2003; Howarth et al. 2019), Great Plains (Karl and Knight 1998; Kunkel 2003; Feng et al. 2016), and Midwest (Kunkel et al. 1999; Groisman et al. 2012; Feng et al. 2016). Quantifying the changes in extreme precipitation and the thresholds that define these events aids in preparing and mitigating for the new extremes that can occur (e.g., the event of March 2019 MoRB flood; Flanagan et al. 2020).

Hence, the goal of this study is to analyze and quantify the spatial and temporal changes in extreme precipitation within the MoRB. For this purpose, we have analyzed data for both annual and seasonal time scales. A wide variety of methods can be found for extreme precipitation analyses, such as extreme value statistical analysis (cf. Barlow et al. 2019), trend analysis (Kunkel 2003; Groisman et al. 2005; Howarth et al. 2019), return-period analysis (Kunkel 2003; DeGaetano 2009), all of which are appropriate for the study of extreme precipitation. To fulfill the objective of this study, we used a station-based trend analysis and a frequency analysis following an approach from Howarth et al. (2019), described in the data and methods section. Moreover, we used box plot analysis to gauge the spread of the extreme events across the MoRB, and multiple seasonal analyses to explain the nature of extreme precipitation in the MoRB. We are unaware of studies solely focusing on extreme precipitation over the MoRB. Thus, it is critical to investigate extreme precipitation within the region using observational data, especially in the context of climate change. Our study fulfils this need.

\section{Data and methods}

\section{a. Station data criteria}

As noted previously, the study area for this analysis is the MoRB region, along with portions of the north-central United States outside of the MoRB region (Fig. 1). This area consists of North Dakota, South Dakota, Nebraska, Kansas, along with portions of Iowa (west of $95^{\circ} \mathrm{W}$ ), Montana (east of $110^{\circ} \mathrm{W}$ ), Wyoming (east of $107^{\circ} \mathrm{W}$ ), and Colorado (east of $105^{\circ} \mathrm{W}$ ). Moreover, it was defined in a way so that it is possible to include as much area in the High Plains region of the United States and the MoRB, without the influence of mountainous regions on the extreme precipitation climatology. The eastern MoRB for this study is defined as the area within the MoRB east of $100^{\circ} \mathrm{W}$ and the western MoRB is the area west of $100^{\circ} \mathrm{W}$. While the number of stations in the eastern MoRB is larger than in the western MoRB, modified analysis taking into account the difference in station coverage (analyzing grid boxes with equal numbers of stations and normalizing results based on number of stations included in the counts) shows that this has no impact on the results comparing the eastern and western MoRB. U.S. Historical Climatology Network (USHCN; http:// doi.org/10.7289/V5D21VHZ) daily, version 3, data were chosen due to the long period of record, its quality, and spatial density of observations. A total of 131 stations with a data record from 1 January 1950 to 31 December 2019 and with a maximum of $10 \%$ missing data were chosen (Fig. 1). Of these 131 stations, 108 had less than 5\% missing data, and 43 stations had less than $1 \%$ missing data. However, to achieve a better spatial representation of precipitation in the study area the missing data threshold was set to $10 \%$ or less. Although biases such as the 5/10 bias or the underreporting of $0.05 \mathrm{~mm}$ or less precipitation totals (Daly et al. 2007) are well known, the USHCN station data represent the longest and the most widely observed climatological records of surface variables.

\section{b. Extreme event definition}

Similar to the approach used by Howarth et al. (2019), the definition of an extreme precipitation event for this study is any daily accumulation event that crosses the top 1\% (99th percentile) of all daily precipitation accumulations, without including no precipitation days. The station based (per station) 99th percentile was defined to identify spatial changes in extreme events across the large study area using a localized climatology (station level) to identify small-scale (local) shifts in extreme precipitation intensity and frequency. The all-station 99th percentile was defined using a basinwide climatology and is thus useful in determining the impact of changes in the nature of extreme precipitation across the region. Because of the seasonality of precipitation within the MoRB region (Wise et al. 2018), all analyses were additionally completed on seasonal (3-month period) time scales. For the results shown below, winter is defined by the months of December-February (DJF), spring is defined by March-May (MAM), summer is defined by June-August (JJA), and autumn is defined by September-November (SON). Analysis was conducted on a second 3-month period time scale [January-March (JFM), April-June (AMJ), July-September (JAS), and October-December (OND)] to see if this shift reflects a better correspondence between the LLJ's developing phase and precipitation response during warm seasons. The GPLLJ, especially in the north-central United States, has been increasing in frequency from March/April until June and decreasing in frequency from July through September during the peak period of GPLLJ frequency (Doubler et al. 2015). In terms of intensity, the southerly flow is stronger during the colder months (October-March), but the frequency is much lower relative to the April-September period (Doubler et al. 2015). It should be noted that due to the large latitudinal and longitudinal range of the study region, frozen precipitation can occur over a wide range of seasons. In this 
study, the frozen precipitation is included in the form of its liquid equivalent quantity. Thus, the frozen precipitation state variables such as snow, sleet, and hail are not investigated separately.

The temporal increase or decrease (i.e., trends) in extreme precipitation frequency (counts) and intensity (annual maximum and 99th percentile) were calculated using a Theil-Sen's trend estimator built into the National Center for Atmospheric Research (NCAR) Command Language (NCL; https://doi.org/ 10.5065/D6WD3XH5). The Theil-Sen trend estimation method is insensitive to outliers and is significantly more accurate than simple linear regression techniques (Wilcox 2001). It is computed by fitting a line through all pairs of points within the dataset and then determining the median of the slopes calculated from those lines. Along with the Theil-Sen trend estimator, we utilized the Mann-Kendall trend significance test to determine the significance of the estimated trends. The MannKendall test is a rank-based, nonparametric (distribution free) significance test that compares the differences in signs between earlier and later data points to detect any trends within the chronological data (Mann 1945; Kendall 1975). This is calculated by summing the sign of all differences in the dataset to calculate the Mann-Kendall statistic $S$, which is used to calculate the variance $V(S)$ and standardized test statistic $Z$, as shown below:

$$
\begin{aligned}
& S= \sum_{i=1}^{n-1} \sum_{j=i+1}^{n} \operatorname{sgn}\left(X_{j}-X_{i}\right), \\
& \operatorname{sgn}\left(X_{j}-X_{i}\right)= \begin{cases}+1, & \left(X_{j}-X_{i}\right)>0 \\
0, & \left(X_{j}-X_{i}\right)=0, \\
-1, & \left(X_{j}-X_{i}\right)<0\end{cases} \\
& V(S)= \frac{1}{18}\left[\begin{array}{ll}
n(n-1)(2 n+5) \\
\left.-\sum_{p=1}^{q} t_{p}\left(t_{p}-1\right)\left(2 t_{p}+5\right)\right],
\end{array}\right] \text { and } \\
& Z= \begin{cases}\frac{S-1}{\sqrt{V(S)}}, & S>0 \\
0, & S=0 \\
\frac{S+1}{\sqrt{V(S)}}, & S<0 .\end{cases}
\end{aligned}
$$

In the above equations, $X_{j}$ and $X_{i}$ are the observations in chronological order, $n$ is the length of the time series, $q$ is the number of tied groups, $t_{p}$ is the number of observations in the $p$ th tied group. $Z$ values above 0 indicate a positive trend, with $Z$ values below 0 indicating a negative trend, with the null hypothesis being rejected if $|Z|$ is greater than 1.96 for a $p$ value of 0.05 (5\% significance). Annual trends were estimated using a time series of annual maximum events or 99th-percentile thresholds, while the seasonal trends were estimated using a time series of events or thresholds computed from each 3-month period representing winter (DJF), spring (MAM), summer (JJA), and autumn (SON). If autocorrelations in any time series (99th percentile and annual maximum) were detected (any correlation above 0.1635 or below -0.1789 using an $N$ of 131 using a two-tailed test confidence interval; Ahmad et al. 2015) split-cosine-bell tapering (prewhitening) was completed using a built-in NCL command ("taper") on $10 \%$ of the time series. After tapering was completed, no autocorrelations were detected within the final analyzed time series used within this study. Comparison between results with and without tapering indicated that tapering did not significantly impact our analysis, all figures impacted were nearly identical regardless of whether tapering was completed. Given that tapering the statistically significant autocorrelated time series is more robust, these analyses were included in this work.

To analyze the frequency of extreme precipitation events in the MoRB, an objective definition of a heavy precipitation event was used, similar to the approach used by Howarth et al. (2019) for their Figs. 5-7. If any event exceeded a threshold $(50,100$, or $150 \mathrm{~mm})$ it was counted only once for each day (unique event definition). This was to remove the impact of a single precipitation event across multiple stations. This definition does not account for the spatial impact of these events, thus a complementary analysis taking into account any event exceeding any of these three $(50,100$, or $150 \mathrm{~mm})$ thresholds was also conducted (not shown). This analysis, when compared with the unique event definition (event only counted once per day), can give a sense into the frequency and size of these events. Both methods showed similar percentage increases (the all-events definition showed only a $4 \%$ larger increase in events when comparing the before and after 1985 periods for all three thresholds) of events along with statistically significant trends, thus it appears that only the frequency of these events is shifting, not the size of the particular events.

\section{Results}

\section{a. Annual and seasonal station maximum precipitation}

Prior to discussing the extreme precipitation event climatology, it is worth investigating station maximum precipitation events in conjunction with the annual total precipitation climatology. Thus, here we provide an overview of extreme events in the study area and facilitate a comparison between the spatial and temporal nature of extremes and the annual precipitation climatology of the region. In the MoRB, climatologically, annual precipitation decreases from east to west (Fig. 1), as does the annual station maximum precipitation (Fig. 2), with a station maximum daily precipitation amount around $225 \mathrm{~mm}$ in the southeast to around $75-100 \mathrm{~mm}$ in the northwest. This gradient of station maximum from south to north is likely driven by the reduced amount of atmospheric moisture in the northern Great Plains relative to the central Great Plains (Mo and Higgins 1996). Although, by assessing the distribution of annual station maximum precipitation events (Fig. 3) it is evident that the very large $(\geq 150 \mathrm{~mm})$ events are not exclusively in the eastern portion of the domain. Stations to the west (left-hand side of Fig. 3) show these large ( $\geq 150 \mathrm{~mm}$ ) events, even as the median event precipitation amount decreases. This includes the single-day largest precipitation event of Colorado $(281.4 \mathrm{~mm})$ that was observed in Holly, 
(a)

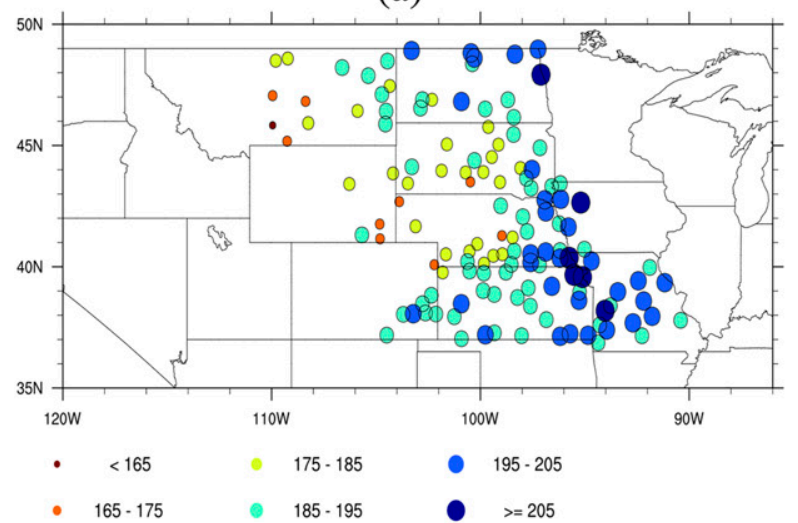

(c) DJF

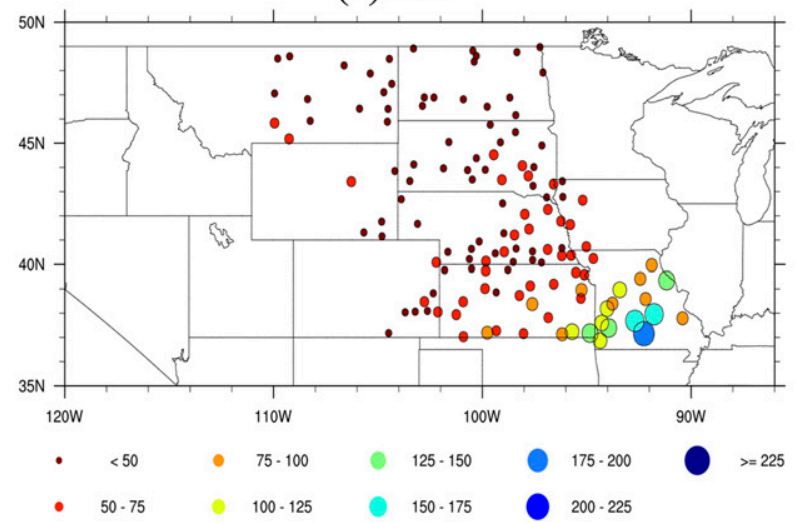

(e) JJA

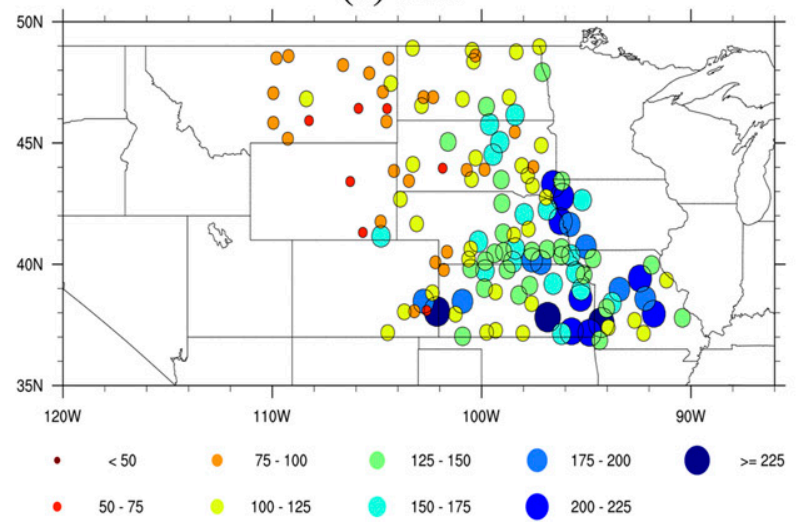

(b) Annual

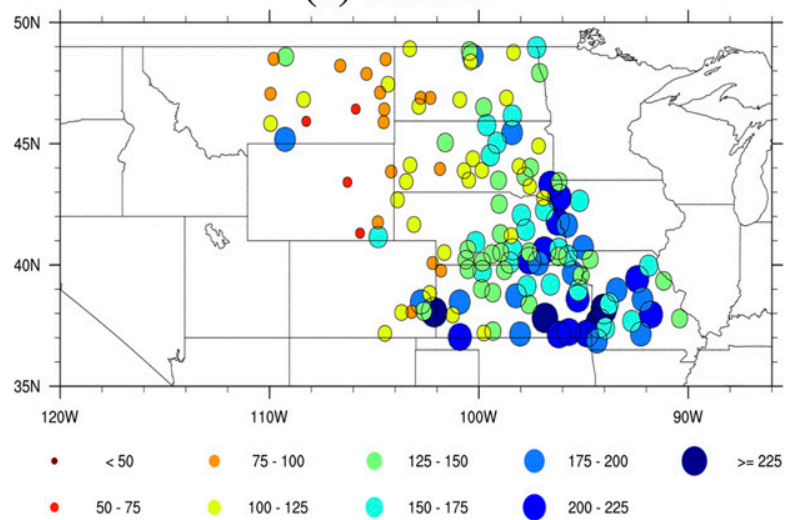

(d) MAM

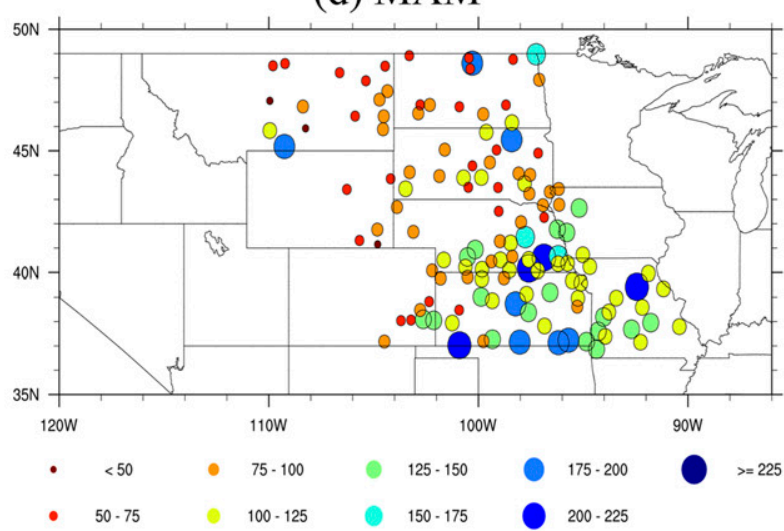

(f) $\mathrm{SON}$

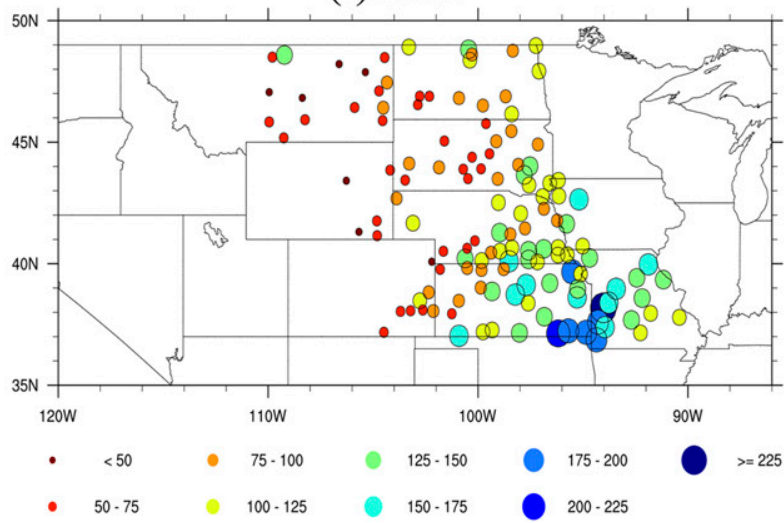

FIG. 2. (a) Average date of annual station daily maximum precipitation event. Also shown is the station daily maximum precipitation amount (mm) between 1950 and 2019 for (b) annual, (c) DJF, (d) MAM, (e) JJA, and (f) SON.

Colorado, on 17 July 1965 (https://coflood2013.colostate.edu/ compare.html).

Seasonally (Figs. 2c-f), the primary occurrence for seasonal precipitation extreme events is during the spring (Fig. 2d), summer (Fig. 2e), and autumn (Fig. 2f) in the southern region of the MoRB. Although station maximum precipitation events do occur during the spring (Fig. 2d) and autumn (Fig. 2f), the spatial coverage and magnitude of maximum precipitation events in the summer (Fig. 2e) is greater than both in the spring and autumn. In the northern MoRB, station maximum precipitation events appear to be distributed throughout the year. Station maximum events occur in Montana and North Dakota in the spring, summer, and autumn. However, a majority of the station maximum events occur in the summer. Only a single station maximum precipitation event occurred in the winter and it was in south-central Missouri (Fig. 2c). This is expected, as the average Julian day in which the annual station maximum precipitation occurs is in the summer months. Specifically, they 


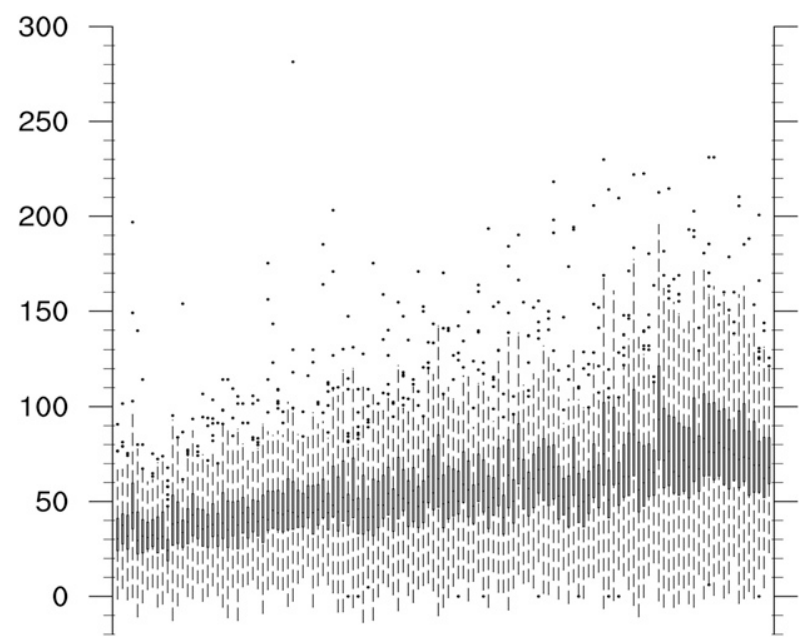

FIG. 3. Box-and-whisker plot for the annual (1950-2019) station maximum daily precipitation amount $(\mathrm{mm})$. Stations are ordered by longitude west to east; the left-hand side of the plot is the westernmost station, and the right-hand side of the plot is the easternmost station. The dots above and below the box-and-whisker plots represent data points that are 1.5 times the IQR above or below the 75th and 25th percentiles, respectively. The IQR was used in this way to detect any outliers within the dataset and to show the full spread of the values away from the median.

occur during June in the west and July and August in the east (Fig. 2b). The large reduction in magnitude of winter station maximum precipitation was also an expected result. Precipitation during the winter is largely frozen and the liquid equivalent amounts during this season are particularly low to the north.

Trend analysis (Fig. 4a) shows that small pockets of areas are recording an increase in annual station maximum precipitation. However, no large continuous region has observed a statistically significant increase or decrease in annual station maximum precipitation events. The geographically scattered statistically significant positive trends can be found in central and western Kansas, Nebraska, South Dakota, eastern Montana, Wyoming, and Colorado. Predominantly, the statistically significant trends have magnitudes around $0.3-0.5 \mathrm{~mm} \mathrm{yr}^{-1}$, which equates to about $3-5 \mathrm{~mm}$ decade $^{-1}$. No statistically significant annual negative trends were found.

In addition, seasonal trends of station maximum precipitation (Figs. 4b-e) do not show statistically significant trends over large contiguous areas in spring (Fig. 4c) or summer (Fig. 4d). In the summer, an area along south-central Nebraska and north-central Kansas border reports stations with negative trends and these stations are surrounded by stations with large positive trends. These negative trends were not limited only during summer season but also can be found at the annual time scale (statistically not significant). In autumn (Fig. 4e), a number of stations in southeastern South Dakota and northeastern Nebraska record statistically significant trends. While this geographic area initially appears to show trends impacted by singular precipitation events in the earlier or later years of the 1950-2019 time series, analysis of the individual station maximum precipitation during autumn (not shown) suggests that this is not the case. In the winter (Fig. 4b), a number of stations in Kansas and Missouri show statistically significant positive trends for the 1950-2019 period.

\section{b. Annual and seasonal extreme precipitation event analysis}

The distribution of annual per-station 99th-percentile thresholds (Fig. 5) is similar to that of the annual station maximum precipitation distribution. The median lowers from east to west, from around $50 \mathrm{~mm}$ in the east to $20 \mathrm{~mm}$ in the west. Box-and-whisker plots suggest that the range of annual per-station 99th-percentile thresholds also decrease from east to west. However, while in the western portion of the study area annual station maxima could be large, the annual per-station 99th-percentile thresholds and interquartile range (IQR) are smaller relative to those for the eastern stations. This is due to the reduced precipitation values that typically occur farther to the west and north within the MoRB, while large ( $\geq 150 \mathrm{~mm}$ ) events are still possible. Even with the reduced variability in the per-station 99th-percentile thresholds of the western region, when accounting for all precipitation events (any day with over $0.0 \mathrm{~mm}$ of precipitation) across the region together into a single distribution, the 99th-percentile threshold is $55.4 \mathrm{~mm}$.

Interestingly, the annual station per-station 99th-percentile trend analysis (Fig. 6a) depicts a similar spatial pattern when compared with the station maximum precipitation trend analysis. The magnitude of the trends is not as large as the station maximum trends. This is an expected result that is due to the large reduction in precipitation magnitude between the station maximum and per-station 99th percentile at each station.

The similarity between the two trend analyses also applies to the seasonal analysis of station per-station 99th percentiles. The per-station 99th-percentile analysis for the summer (Fig. 6d) has few statistically significant trends across the entire study area, which is similar to that of the summer station maximum trend analysis. However, stations with statistically significant results across bordering areas of south-central Nebraska and north-central Kansas were not observed in the per-station 99thpercentile trend analysis for the summer. The winter (Fig. 6b) and autumn (Fig. 6e) spatial patterns in the station maximum analysis is observed again in the per-station 99th-percentile trend assessment. In winter, a larger number of stations demonstrate a statistically significant increase in the southern portion of the domain. In autumn, a group of stations in northeastern Nebraska and southeastern South Dakota are showing a statistically significant increase, same as in the station maximum analysis. However, the spring per-station 99th-percentile trend analysis (Fig. 6c) is different than the spring station maximum trend analysis. In addition, the spring and winter per-station 99th-percentile trend analysis suggests a similar spatial pattern of statistical significance, with a large number of stations being statistically significant in the southern portion of the study area.

\section{c. Distribution of extreme events in the MoRB}

Given the extensive range of annual per-station 99th-percentile thresholds, it is worth investigating the distribution of heavy to extreme precipitation events, especially those near or over the all-station 99th percentile $(55.4 \mathrm{~mm})$. The $\geq 50 \mathrm{~mm}$ precipitation 


\section{(a) Annual}

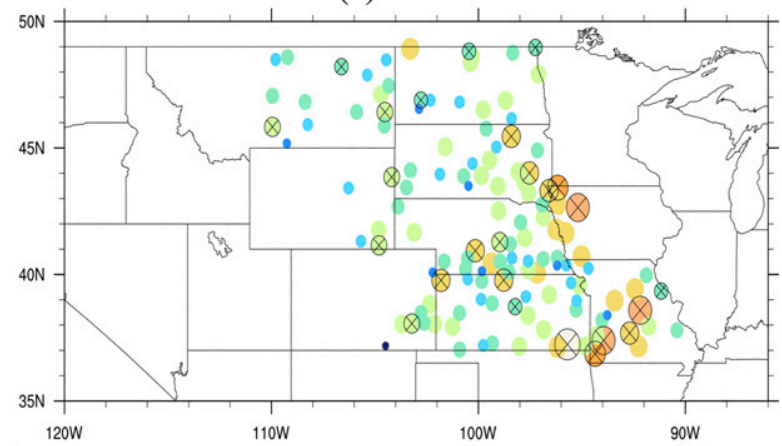

(b) DJF

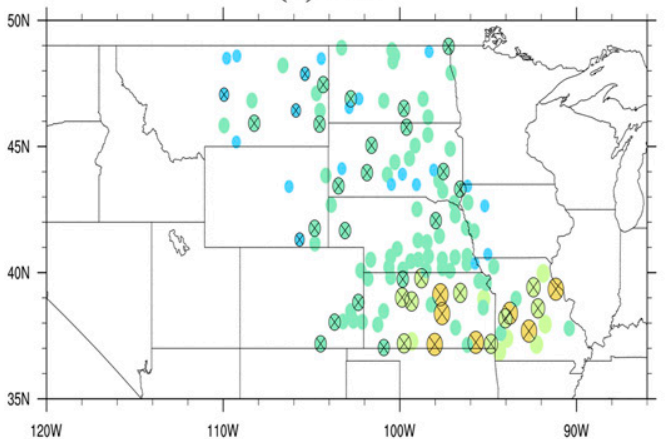

(d) JJA

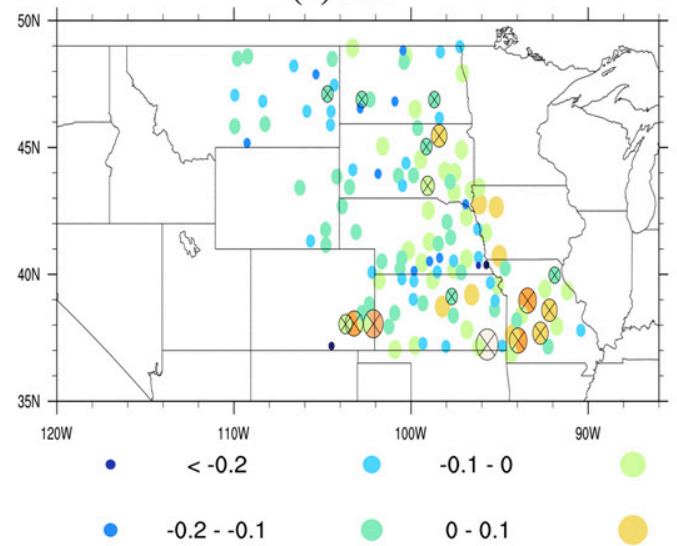

(c) MAM

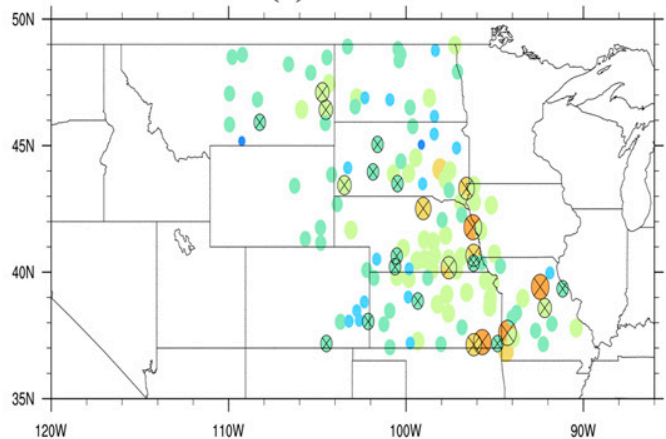

(e) $\mathrm{SON}$

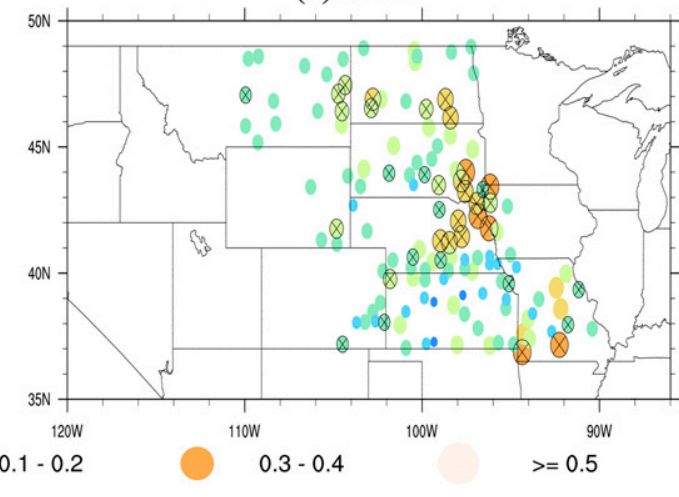

$0.4-0.5$

FIG. 4. Regression slope analysis of annual maximum daily precipitation event by station for (a) annual, (b) DJF, (c) MAM, (d) JJA, and (e) SON. The size of the circle and its color denote the magnitude (larger circles denote increased magnitudes) determined through a Theil-Sen trend estimation method, with the circles including an X showing a statistically significant trend determined with a Mann-Kendall trend significance test. Prewhitening was completed on any station with a statistically significant autocorrelation (two-tailed $t$ test with an $N$ of 131).

distribution (Fig. 7a), roughly the 99 th percentile of $55.4 \mathrm{~mm}$, suggests 40-90 unique events have occurred each year. Between the periods of 1950-85 and 1985-2019, there was an increase from 1956 to 2291 events, a $15 \%$ positive change. Precipitation events of $\geq 100 \mathrm{~mm}$ (Fig. $7 \mathrm{~b}$ ) are less frequent, about 5-20 events $\mathrm{yr}^{-1}$. However, there was a greater increase in $\geq 100 \mathrm{~mm}$ precipitation events with 263 occurring between 1950 and 1985 and 337 occurring between 1985 and 2019, a 22\% increase. Precipitation events of $\geq 150 \mathrm{~mm}$ (Fig. 7c), which are not very common (around 0-5 events $\mathrm{yr}^{-1}$ ), have increased from 35 events between 1950 and 1985 to 55 events between 1985 and 2019, which is a $36 \%$ increase. Thus, all three distribution categories, $\geq 50, \geq 100$, and $\geq 150 \mathrm{~mm}$, show an increase in events after 1985. However, the difference in total events before and after 1985 is not statistically significant for any of the three distribution categories. Nonetheless, each distribution category ( $\geq 50, \geq 100$, and $\geq 150 \mathrm{~mm}$ ) shows a statistically significant increasing trend from 1950 to 2019.

Spatially, all-station 99th-percentile ( $\geq 55.4 \mathrm{~mm}$ ) precipitation events occur predominantly in the southeastern portion of 


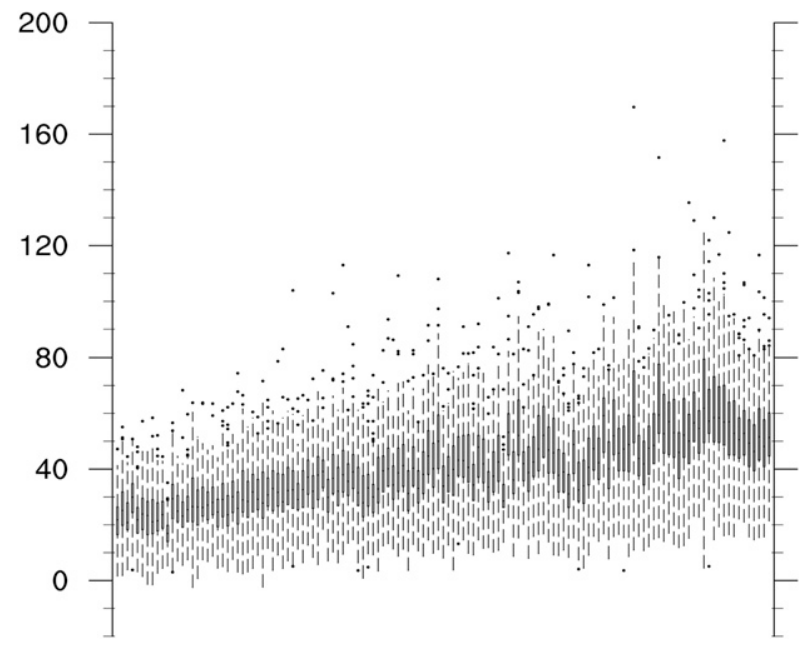

FIG. 5. Box-and-whisker plot for the annual (1950-2019) station 99th percentile of precipitation $(\mathrm{mm})$. Stations are ordered by longitude west to east; the left-hand side of the plot is the westernmost station, and the right-hand side of the plot is the easternmost station. The dots above and below the box-and-whisker plots represent data points that are 1.5 times the IQR above or below the 75 th and 25 th percentiles, respectively.

the study domain (Fig. 8). From 1950 to 2019, approximately 125-175 all-station 99th-percentile events were recorded across southeastern Kansas and Missouri. In the central MoRB, east of $100^{\circ} \mathrm{W}$ in Nebraska and Kansas, the number of all-station 99th-percentile events are about 100 while it is less than 25 events for west of $100^{\circ} \mathrm{W}$. Since these events were identified at each station (not unique events in this case), the sparsity of stations farther to the west could be reducing the number of events observed. Nonetheless, because of much higher annual precipitation amounts in the east (Fig. 1), it is likely that these all-station 99th-percentile events are more common in the southeastern MoRB stations than in the western stations.

The spatial analysis of seasonal all-station 99th-percentile events depicts more events in the summer and fewer events in the winter. Winter all-station 99th-percentile events (Fig. 8b) are particularly rare across most of the study domain, with only a few events occurring in the southeastern MoRB. Autumn (Fig. 8e) and spring (Fig. 8c) are very similar, with southeastern all-station 99th-percentile events occurring more frequently than in the winter season. Around 40-60 events are common during the spring and autumn across the southeast (Missouri, Kansas, and Nebraska), with a few stations in the north and west (Montana, Wyoming, Colorado, North Dakota, and South Dakota) observing more than 10 events.

The predominant season for these all-station 99th-percentile events is the summer (Fig. 8d), with more events than the other three seasons combined. In the southeastern portion of the study area, around 50-70 events are common with some stations showing nearly 100 events during the summer from 1950 to 2019. In the north and west, most stations show between 20 and 40 events, which is nearly equal to their annual total from 1950 to 2019. Thus, most of the all-station 99th-percentile events in the western portion of the MoRB occur in June, July, or
August. An analysis of all all-station 99th-percentile events east and west of $100^{\circ} \mathrm{W}$ through all 4 seasons (Fig. 9) shows this result. Overall, in the western part of MoRB (west of $\left.100^{\circ} \mathrm{W}\right), 594$ events were observed during the summer while 350 for the other three seasons combined. While in the eastern region (east of $100^{\circ} \mathrm{W}$ ) 3027 occurred during the summer and 3189 for the other seasons. The low winter season all-station 99th-percentile event total in the eastern (197) and western regions (4) of the MoRB is not surprising. This result is due to the low snow water equivalent values in the higher-latitude regions of the western MoRB (Baxter et al. 2005).

\section{Discussion}

\section{a. Impacts of extreme precipitation}

The climatology of water equivalent precipitation across the MoRB study area is varied. In the eastern region, climatological annual totals are around $700-900 \mathrm{~mm} \mathrm{yr}^{-1}$, with a gradual decrease toward the north and west to around $200-400 \mathrm{~mm} \mathrm{yr}^{-1}$. The all-station-based 99 th percentile $(55.4 \mathrm{~mm})$ represents a substantially different percentage of the annual total, from around 1/16th of the annual precipitation total in the east to $1 / 5$ th of the annual total in the west. Although the frequency of all-station 99th-percentile events in the western regions of the MoRB is low, events above 100 and $150 \mathrm{~mm}$ do occur, and they can be particularly devastating as they would produce between one-third and one-half of the annual climatological precipitation total (Fig. 1). While such ( $\geq 100$ or $\geq 150 \mathrm{~mm}$ ) events would still be impactful in the eastern MoRB, they would not result in significant societal impacts like in the western MoRB. The examples of past flash floods events of Black Hills (June 1972) and Kansas City (August 1977) describe this well. While both events were impactful, with comparable precipitation amounts, the damage and loss of lives in the 1972 Black Hills event (\$160 million in damages and 237 lives lost) were far greater than in the 1977 Kansas City event ( $\$ 50$ million in damages and 25 lives lost).

Surface hydrological conditions in the region of the extreme event, in conjunction with the intensity of the rainfall, would determine the short-term impact of the extreme precipitation event (Davis 2001; Rozalis et al. 2010). Conditions that increase surface runoff would increase the magnitude of flooding during any heavy rainfall event, especially during extreme events. Thus, linking the extreme precipitation discussed here with the climatological surface hydrological state of each season would provide an idea of magnitude of the impacts. Most of the extreme precipitation events occur during the summer, when soil moisture levels vary notably owing to relatively lower climatological precipitation totals in comparison with spring and increasing near-surface temperatures (Flanagan et al. 2017). Vegetation growth in the region would cause soil moisture content to generally decline without recharge from irrigation or precipitation (Yang et al. 1998). Spring and autumn represent the transition seasons for temperature, precipitation, and thus soil moisture. During the spring, rising temperatures (Flanagan et al. 2017; Wise et al. 2018) cause an increase in biomass and result in decrease in soil moisture content even as water 
(a) Annual

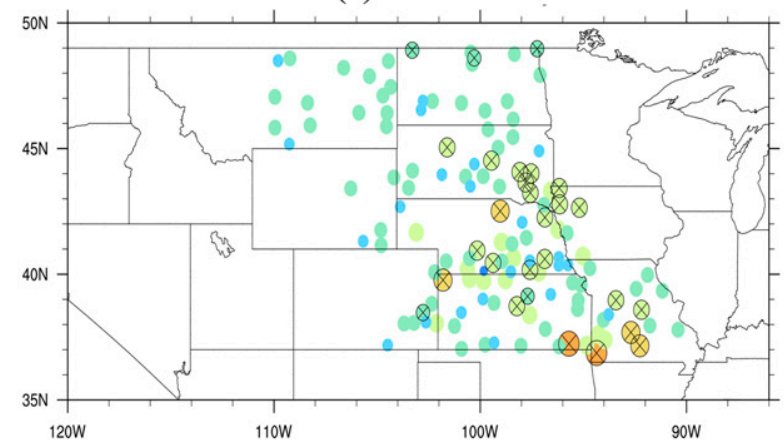

(b) DJF

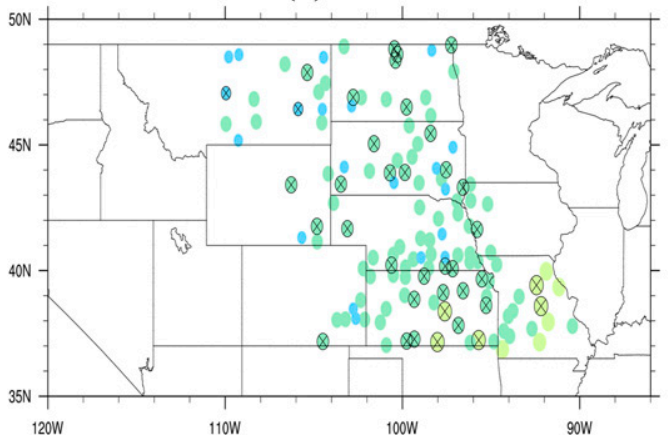

(d) JJA

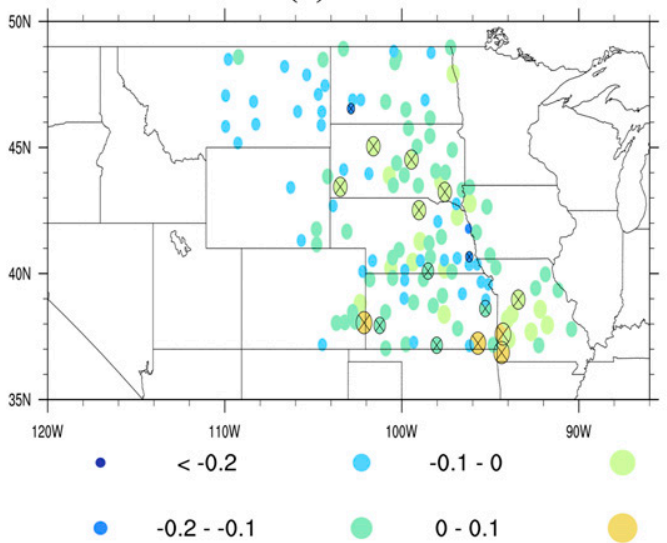

(c) MAM

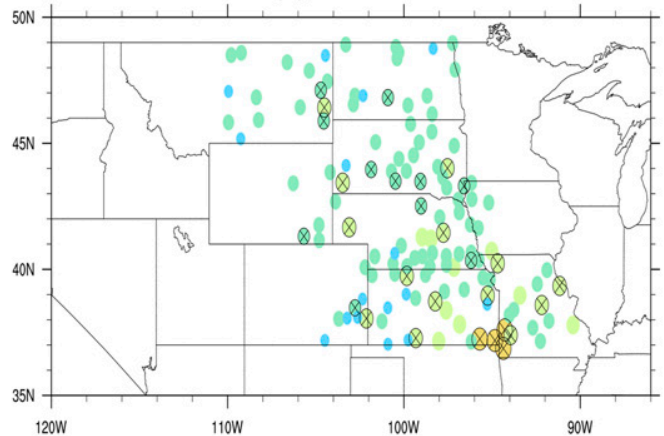

(e) SON

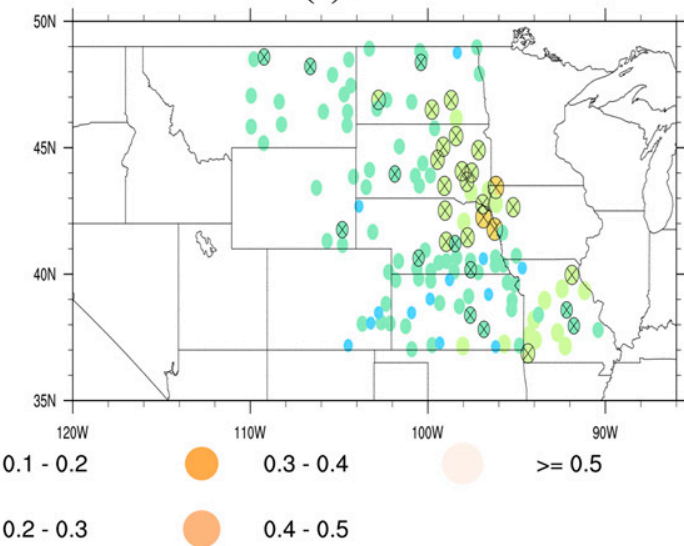

FIG. 6. Regression slope analysis of per-station 99th-percentile threshold for (a) annual, (b) DJF, (c) MAM, (d) JJA, and (e) SON. The size of the circle and its color denote the magnitude (larger circles denote increased magnitudes) determined through a Theil-Sen trend estimation method, with the circles including an X showing statistically significant trend determined with a Mann-Kendall trend significance test. Prewhitening was completed on any station with a statistically significant autocorrelation (two-tailed $t$ test with an $N$ of 131).

equivalent precipitation increases. During autumn, declining temperatures (Flanagan et al. 2017; Wise et al. 2018) and a decrease in biomass due to harvest, along with the still present water equivalent precipitation, causes an increase in soil moisture going into winter.

During a normal year, this would mean that moisture from precipitation events would be partially stored into the soils during all three seasons. If antecedent soil moisture is too high (wet) or low (dry), then precipitation would primarily result in runoff (Noguchi et al. 1997) and potentially overwhelm regional water storage infrastructure. Given the connection with varying surface hydrological states, the impact of the 99th-percentile precipitation events would also be varied, from flash flooding that regional and local watersheds could manage or large runoff events that lead to major flooding events. While a drought or pluvial year would certainly impact the chance of incurring a 99th-percentile precipitation event, the impact of such events would be magnified during these years. This would be especially true if a large-scale extreme precipitation event were to happen during a hydrologically extreme year, as occurred in March 2019 (Flanagan et al. 2020) when a warm, wet early winter followed by a frigid, wet late 
(a)

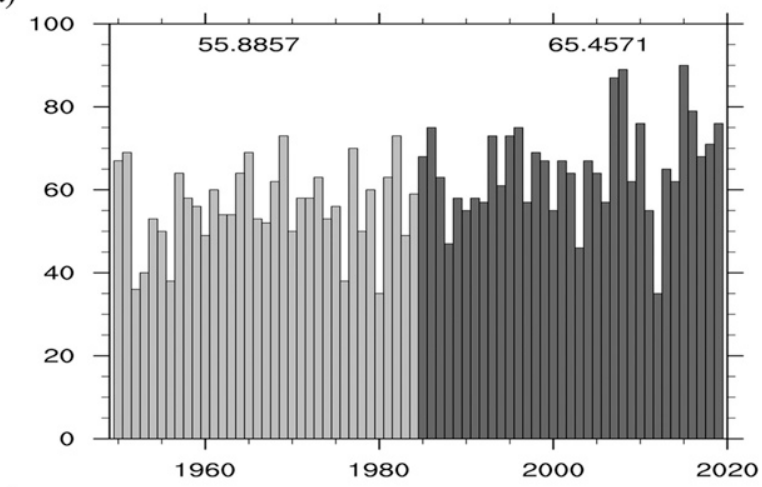

(b)

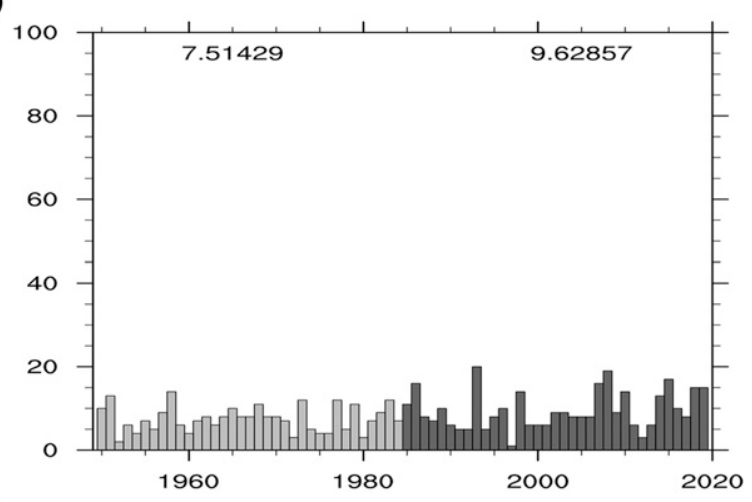

(c)

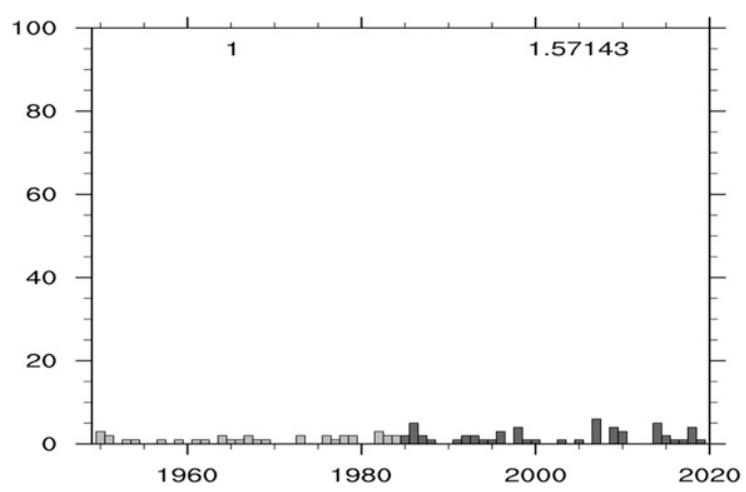

FIG. 7. Annual count of unique (only one event counted per day, per year) precipitation events over (a) 50, (b) 100 , and (c) $150 \mathrm{~mm}$ across the study region. Light-gray bars are for events before 1985, and events after 1985 are shown with dark-gray bars. The numbers on the top of each plot represent the prior-to-1985 (left-hand side) and after-1985 (right-hand side) average number of events per year during that period.

winter led to record-breaking widespread flood within the southern MoRB.

Winter season presents a much more complicated situation than do the other three seasons. As temperatures in many states of the MoRB are below freezing levels during this time of a year (Flanagan et al. 2017; Wise et al. 2018), much of the hydrological system can be covered in ice. Thus, as surfaces are frozen and impermeable, an extreme water equivalent precipitation event could be particularly impactful. In addition, a 99th-percentile rain-on-snow event could multiply the flooding potential with the addition of the melting snow (McCabe et al. 2007; Freudiger et al. 2014) into the hydrologic system. While winter season 99th-percentile events are extremely rare in the northern MoRB due to below-freezing temperatures and low atmospheric moisture, they could be exceptionally impactful if the event occurs as water equivalent precipitation due to frozen rivers and soils. In the southern MoRB, these events are also rare, but occur more frequently than in the northern MoRB. Again, the impact of these southern MoRB 99th-percentile events would be conditioned on the hydrologic context of that year. For a colder year, soils and water bodies would be frozen leading to increased runoff after a water equivalent precipitation event. However, because near-surface climatological temperatures do not fall below freezing in the southern MoRB, this situation is not as common as compared with the northern MoRB. Thus, a more typical situation would be an extreme precipitation event occurring over moist soils and reduced stream, river, and reservoir water levels (Ettema and Zabilansky 2004; Maurer and Lettenmaier 2004; Wise et al. 2018). Thus, runoff would likely be increased due to the moist soils, but with water reservoirs and other storage infrastructure, the region would be able to handle additional water and the impacts would be reduced.

\section{b. Causes and impacts of temporal trends}

While all forms of precipitation can occur within the MoRB region, convection is the primary cause of precipitation. Specifically, mesoscale convective systems (MCSs; Fritsch et al. 1986) are the predominant driver of warm season precipitation in the eastern MoRB and north-central United States. This explains the reduction of station maximum precipitation and the per-station 99th percentile for precipitation toward the north and west as compared with the southern and eastern MoRB. MCSs form in the lee of the Rockies and propagate eastward toward the eastern MoRB states (Tuttle and Davis 2006), producing nocturnal severe weather events and copious amounts of precipitation (Wallace 1975). Reif and Bluestein (2017) showed nocturnal elevated storms, in conjunction with nocturnal MCSs, are a primary driver of nocturnal rainfall over the central United States. Thus, shifts in precipitation within the MoRB, especially in the warm season, can be linked to differences in magnitudes, frequencies, and/or intensity of convective storms within the MoRB. Recently, research linked increasing precipitation totals across the central United States with the increases in the heaviest precipitation events (Karl and Knight 1998; Groisman et al. 2004, 2005, 2012; Feng et al. 2016). It is also suggested that the mesoscale convection is likely the driver of this change. This does not mean that synoptic large-scale forced precipitation is unimportant, but that the primary driver of precipitation in the warm season, when most of the events occur, is linked to mesoscale convection. Synoptic-scale flow anomalies related to increased moisture transport into the region are crucial for heavy precipitation events (Frei et al. 1998; Zhao et al. 2017; Flanagan et al. 2018, 2020), and thus they cannot be discounted even if they are not the primary driver of the excessive precipitation. 
(a) Annual

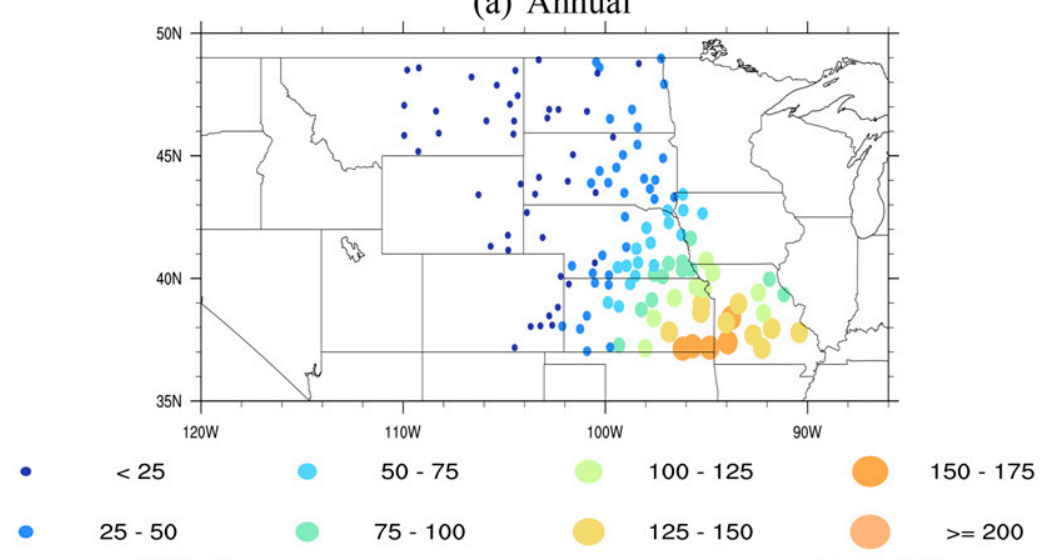

(b) DJF

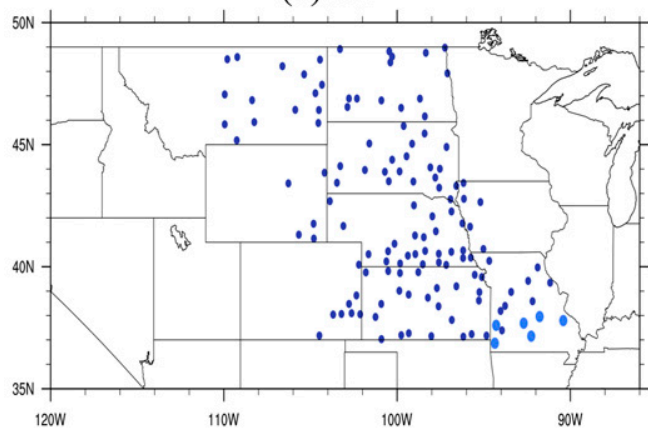

(d) JJA

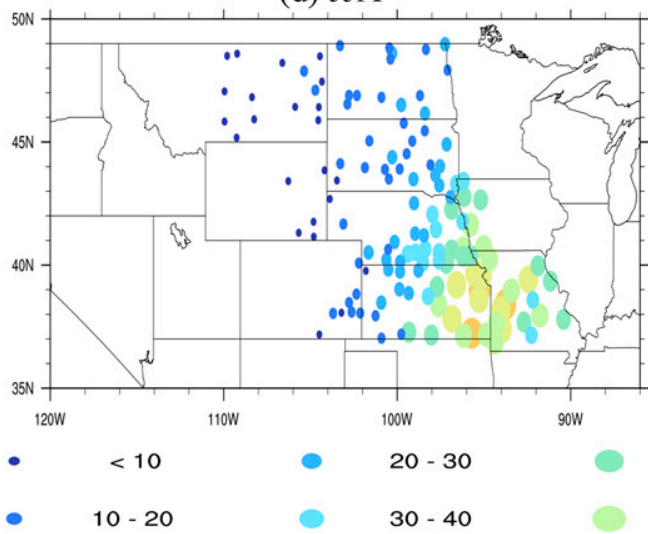

(c) MAM

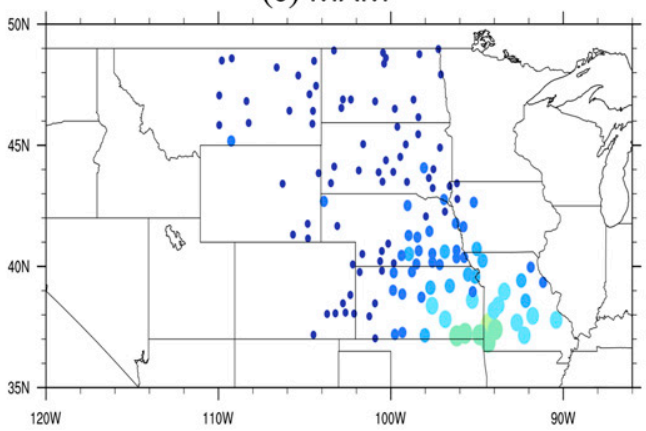

(e) SON

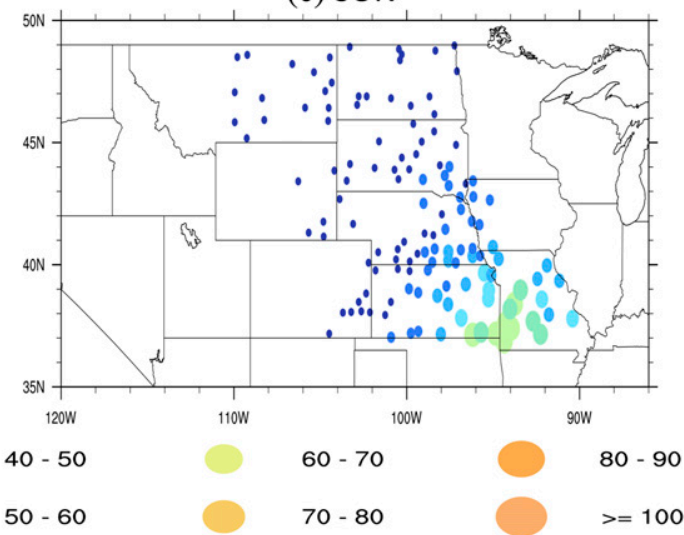

FIG. 8. Count of all precipitation events over the all-station 99th-percentile threshold $(55.4 \mathrm{~mm})$ that occurred over (a) annual, (b) DJF, (c) MAM, (d) JJA, and (e) SON at each station.

Due to the possible impacts of these 99th-percentile precipitation events, changes in their magnitudes would further exacerbate their impacts. Analysis of both station maximum precipitation and per-station 99th percentiles show widespread increasing trends within the MoRB. While the statistical significance is not as prevalent as the positive trends, it appears as though the extreme event thresholds are increasing across most of MoRB. The $1-5 \mathrm{~mm}$ decade $^{-1}$ increases in station maximum precipitation and $1-3 \mathrm{~mm} \mathrm{decade^{-1 }}$ in the per-station 99th percentile would lead to around a $7-35 \mathrm{~mm}$ increase in the climatological station maximum or per-station 99th percentiles across the region. While a $7-\mathrm{mm}$ increase is not particularly large, a $35-\mathrm{mm}$ increase in the 99th percentile is a dramatic increase in the magnitude of extreme events. This magnitude of change in the per-station 99th percentile means that the daily precipitation event of rarest magnitude of the 1950s would be more commonplace in the present day. Related previous research further confirms these findings of our study (Karl and Knight 1998; Groisman et al. 2004, 2005, 2012; Feng et al. 2016; Christian et al. 2015; Weaver et al. 2016; Flanagan et al. 2017, 2018).

Seasonally, trends displayed different statistical significance patterns than those seen for the annual analysis. Summer shows both a scattered spatial distribution of stations with 


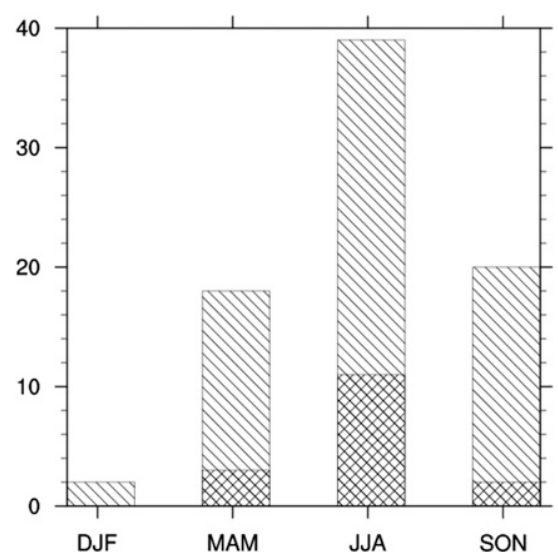

FIG. 9. All precipitation events over the all-station 99th percentile (55.4 $\mathrm{mm})$ across all four seasons for all stations: east (hatched lines) and west (cross hatched lines) of $100^{\circ} \mathrm{W}$. The counts of each season have been normalized by dividing through by the number of stations in each region (east and west of $100^{\circ} \mathrm{W}$ ).

statistically significant trends. In the station maximum trend analysis, a series of stations with negative trends are evident along the Nebraska-Kansas border in the summer. Given the location of the stations with negative trends, this could be linked to irrigation, which is prevalent in the south-central area of Nebraska (Pei et al. 2016). Irrigation would dampen the evolution of surface temperatures while providing large amounts of moisture to the near-surface atmosphere. According to Findell and Eltahir (2003a,b) this could enhance or inhibit chances of convection later in the day dependent on the morning low-level atmospheric state. It was also noted that with an intermediate lapse rate (between dry and moist adiabatic) or closer to moist adiabatic below $300 \mathrm{hPa}$ would favor the enhancement of precipitation over wet soils (seen in Fig. 2a of Findell and Eltahir 2003a). However, given the prevalence of capping inversions and more dry adiabatic lapse rates during the warm season over the central United States (Lanicci and Warner 1991a,b; Ribeiro and Bosart 2018), the environment identified by Findell and Eltahir (2003a,b) favoring precipitation over wet soils does not frequently occur in the southern Nebraska region.

The spring and summer (warm) seasons are the typical time of a year when the GPLLJ brings moisture from the Gulf of Mexico in the central and northern United States (Higgins et al. 1997; Gimeno et al. 2010, 2013). As the GPLLJ is such an important driving force of moisture advection into the region, it is important to investigate the connection between extreme precipitation and the GPLLJ. As such, we have also conducted a shifted seasonal analysis that looked into the AMJ and JAS 3-month periods, which are linked to the peak of the GPLLJ frequency and intensity during the year. This work was completed to explore possibilities of a better linkage between the GPLLJ's development phase and extreme precipitation responses. The JAS analyses of both annual maximum and 99th-percentile trend analyses are similar to the JJA analysis shown in Figs. $4 \mathrm{~d}$ and $6 \mathrm{~d}$ and thus are not shown. However, the AMJ analyses of annual maximum and 99th-percentile trends do present some interesting features. When compared with the MAM analysis for 99th-percentile thresholds and station annual maximum precipitation, the AMJ analyses (Fig. 10) show a more consistent pattern of statistically significant trends in the eastern MoRB. In the MAM analyses (Figs. 4c and 6c), numerous stations in western South Dakota, Nebraska, and Kansas show statistically significant trends, while in the AMJ analyses these significant trends are located in the eastern portions of these MoRB states. As previous work has shown, the GPLLJ has been linked to climate change through a shift in the moisture transport toward the north in the central United States (Cook et al. 2008; Barandiaran et al. 2013; Wimhurst and Greene 2020). The AMJ trends in the eastern MoRB noted in this work could be a result of this noted shift in strength and location of the GPLLJ, although more work is needed to further explore this linkage.

In winter, most stations in Kansas and Missouri show statistically significant positive trends. This result suggests that increasing temperatures, linked to climate change (Qiao et al. 2014), could be causing a climatological shift from frozen to water equivalent precipitation. This would result in an increase in the magnitude of station maximum winter precipitation events and in the per-station 99th percentile because more precipitation is occurring in liquid form than as frozen precipitation.

In autumn, a large area in northeastern Nebraska and eastern South Dakota reported statistically significant increases in both per-station 99th percentiles and station maximum precipitation. Due to the lack of statistically significant trends outside of this relatively small region within the MoRB, it is difficult to conclusively determine the cause of the statistically significant trends in northeastern Nebraska and eastern South Dakota. The trends in the most extreme events and station maximum precipitation are much greater in this area in comparison with the per-station 99th-percentile trend analysis. This shows how the changes in precipitation during this season are likely not systemic, but rather a change to only the most extreme events and their drivers. Climatological winds for the autumn season (not shown) for this area suggest a predominantly southerly wind direction, thus increasing atmospheric moisture from the south could potentially explain the increase in extreme precipitation. This is further supported by the typical source of precipitation during autumn in the MoRB, synoptic waves (Wise et al. 2018). Wise et al. (2018) found that large pressure troughs are common across North America during high-flow years in the MoRB. During autumn, Wise et al. (2018) shows that these pressure troughs are found stretched north to south across central North America, directing surface fronts across the MoRB. As frontal systems reinforce flow from the south prior to their propagation through a region, the increased southerly flow and synoptic and mesoscale forcing for precipitation ahead of surface fronts points toward the increased chances for extreme precipitation given enhanced moisture at this time of year in the MoRB. Thus, modifications to these surface lows, middle atmospheric troughs, or available moisture from the south would increase the frequency and intensity of extreme precipitation during this 
(a)

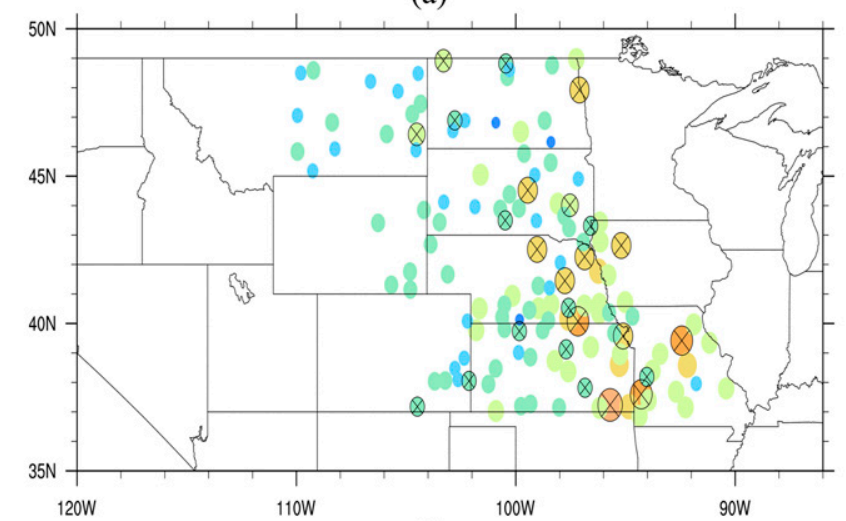

(b)

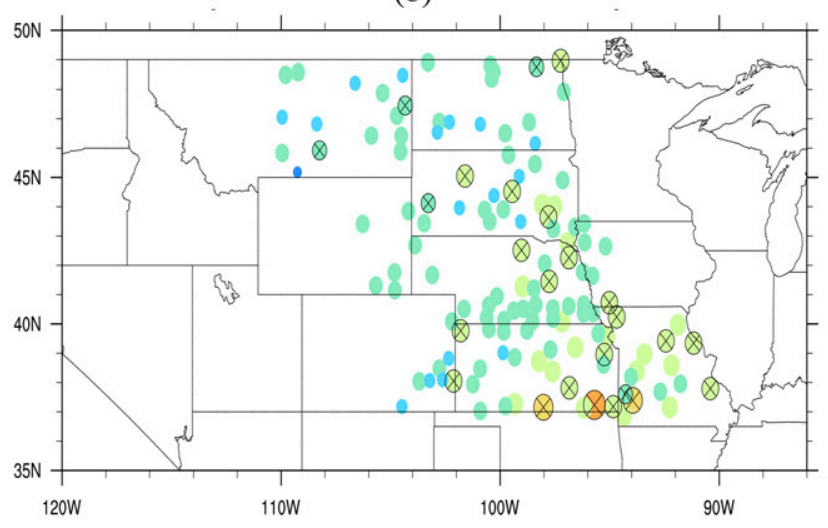

$\begin{array}{lllll}-<-0.2 & -0.1-0 & 0.1-0.2 & 0.3-0.4 & >=0.5 \\ -0.2-0.1 & 0-0.1 & 0.2-0.3 & 0.4-0.5\end{array}$

FIG. 10. Regression slope analysis of (a) annual maximum daily precipitation event by station for AMJ and (b) per-station 99th-percentile threshold for AMJ. The size of the circle and its color denote the magnitude (larger circles denote increased magnitudes) determined through a Theil-Sen trend estimation method, with the circles including an X showing a statistically significant trend determined with a Mann-Kendall trend significance test. Prewhitening was completed on any station with a statistically significant autocorrelation (two-tailed $t$ test with an $N$ of 131).

season. However, further research is needed before drawing a firm conclusion.

\section{Conclusions}

This study examined the nature of extreme precipitation and temporal and spatial changes to extreme precipitation, as defined by and using a 99th percentile (per station and all station) across all precipitation days, across the MoRB. There has been a lack of extreme precipitation studies focusing on this important and complex watershed, especially on a subannual basis. Thus, it is crucial to investigate the nature of changes in extreme precipitation over the MoRB to detect any temporal or spatial shifts. Further, definition of an extreme event is statistical in character and hence shifts in extreme precipitation frequency and magnitudes can change what is defined as an extreme event. In other words, what was once considered a rare, extreme event can be considered normal or not extreme at the present time. Record-breaking extreme events, such as the March 2019 flood of the MoRB (Flanagan et al. 2020), could become more frequent in response to the changing nature of extreme precipitation. The goal of this study was to analyze the temporal and spatial nature of extreme precipitation in the MoRB to understand the climatology of extreme events in the region and to detect any trends within the definitions of such extremes. Further, this study sought to investigate extreme precipitation event statistics on a seasonal basis to determine any shifts in frequency or intensity relating to periods in which the hydrologic state of the region is more vulnerable to such events.

Data spanning the 1950-2019 period from 131 USHCN stations across the MoRB were used to determine the climatology of extreme precipitation. Only stations that contained less than $10 \%$ missing observations were utilized. An analysis 
of station maximum and per-station 99th-percentile precipitation events was completed, with a focus on the temporal and spatial shifts. Climatologically, more precipitation occurs over the course of a year in the eastern MoRB than in the western MoRB. The climatology in station maximum precipitation and the per-station 99th percentile follows the same pattern that is higher in the eastern MoRB than in the western MoRB. Further, analysis showed that the intensity of station maximum precipitation events and the frequency of per-station 99th-percentile events decreased from south to north and from east to west. Overall, our results show the following for the 1950-2019 period:

- Positive trends in station maximum precipitation and the per-station 99th percentile are observed across the MoRB.

- Annually, these trends do not show a spatial pattern of statistical significance across the region.

- Statistically significant increases in the frequency of events with $\geq 50, \geq 100$, and $\geq 150 \mathrm{~mm}$ of precipitation are observed across the region when comparing the periods before and after 1985.

- Increase of events with $\geq 50, \geq 100$, and $\geq 150$ mm of precipitation were observed in all seasons.

- Station maximum precipitation and the per-station 99thpercentile magnitudes are increasing in the southern MoRB states (Kansas and Missouri) and likely linked to increasing temperatures due to climate change.

- Statistically significant increase or decrease in station maximum precipitation is respectively recorded in spring or summer across the bordering areas of north-central Kansas and south-central Nebraska, but no statistically significant shift in the per-station 99th percentile is observed.

- During autumn, an area in northeastern Nebraska and eastern South Dakota showed a statistically significant increase in both station maximum precipitation and the perstation 99th percentile.

- During winter, southern MoRB states (Kansas and Missouri) are experiencing a statistically significance shift in the trends of both station maximum and per-station 99th-percentile precipitation.

- During the spring, the eastern portion of the MoRB depicts statistically significant increases in the intensity of extreme precipitation, likely related to changes in the GPLLJ.

These conclusions agree with the fourth National Climate Assessment (NCA4) (Easterling et al. 2017), which noted an uptick of MCS activity and extreme precipitation in the region during the warm season and suggested linkages to enhanced low-level jets and specific humidity. The report also stated that the north-central U.S. region (including the MoRB) was susceptible to strong climate fluctuations, meaning that extreme precipitation events can produce damaging flood events across the MoRB. Thus, our results showing enhanced and more frequent extreme precipitation, relative to the mid-twentieth century, could result in more intense and frequent flood events for the MoRB such as the March 2019 historical floods in the lower MoRB (Flanagan et al. 2020).

However, temporal trends in all four 3-month periods analyzed show that distinctly different features of the MoRB climate are impacting extreme precipitation in different manners. Shifts in winter extreme precipitation in the southern MoRB can be explained by increased regional temperatures that causes frozen precipitation to become liquid. Changes in the spring and summer, especially per-station maximum precipitation, could be linked to irrigation practices that have become widespread in the region in recent decades (Pei et al. 2016) or climate change effects that shift the GPLLJ exit region poleward (Cook et al. 2008; Barandiaran et al. 2013; Wimhurst and Greene 2020). Also depicted are statistically significant increases in event intensity in the eastern MoRB during autumn. Previous research has shown a connection between increases in total precipitation and extreme precipitation in the midwestern United States and increased moisture convergence related to the GPLLJ (Easterling et al. 2017; Higgins et al. 1997). Our results are likely related to this increase of precipitation in the midwestern United States, given the small spatial coverage of statistically significant stations in the eastern MoRB. This research emphasizes the significant impact that shifts in extreme precipitation can have during a year. Given that the hydroclimate of the MoRB is seasonally varied, shifts in extreme precipitation during a hydrologically vulnerable time of year (i.e., prone to floods) could imply more extreme floods or more frequent floods for the region.

While our study clearly shows a shift in the region's extreme precipitation, more research is needed to fully understand the nature of these shifts in the MoRB. First, an in-depth analysis of frozen precipitation in the western MoRB is needed to determine the nature and shifts in extreme snowfall events. Although snowfall in the eastern MoRB is not as impactful to the MoRB hydroclimate as snowfall in the Rocky Mountains (Wise et al. 2018), an in-depth analysis of nonmountain snowfall in the MoRB is warranted given the winter liquid equivalent results seen in the southeastern MoRB. A detailed analysis of various drivers of the extreme precipitation events (e.g., large-scale moisture advection, LULCC-driven regional and local moisture distributions, shifts in the GPLLJ location, intensity, and frequency) across the MoRB could reveal additional details into the causes of these changes.

Acknowledgments. The authors thank Dr. Dennis Todey and Dr. Dannele Peck for guidance and advice in this work. Dr. Paul Flanagan completed a majority of this work as a postdoctoral researcher for the High Plains Regional Climate Center. We also thank the three anonymous reviewers and the journal editor for their help in refining the work to its current form.

\section{REFERENCES}

Ahiablame, L., A. Y. Sheshukov, V. Rahmani, and D. Moriasi, 2017: Annual baseflow variations as influenced by climate variability and agricultural land use change in the Missouri River basin. J. Hydrol., 551, 188-202, https://doi.org/10.1016/ j.jhydrol.2017.05.055.

Ahmad, I., D. Tang, T. F. Wang, M. Wang, and B. Wagan, 2015: Precipitation trends over time using Mann-Kendall and Spearman's rho tests in Swat River basin, Pakistan. $A d v$. Meteor., 2015, 1-15, https://doi.org/10.1155/2015/431860. 
Appenzeller, C., and H. C. Davies, 1992: Structure of stratospheric intrusions into the troposphere. Nature, 358, 570-572, https:// doi.org/10.1038/358570a0.

Ashraf, M., and K. Habib-ur-Rehman, 1999: Interactive effects of nitrate and long-term waterlogging on growth, water relations, and gaseous exchange properties of maize (Zea mays L.). Plant Sci., 144, 35-43, https://doi.org/10.1016/S0168-9452(99)00055-2.

Barandiaran, D., S. Y. Wang, and K. Hilburn, 2013: Observed trends in the Great Plains low-level jet and associated precipitation changes in relation to recent droughts. Geophys. Res. Lett., 40, 6247-6251, https://doi.org/10.1002/2013GL058296.

Barlow, M., and Coauthors, 2019: North American extreme precipitation events and related large-scale meteorological patterns: A review of statistical methods, dynamics, modeling, and trends. Climate Dyn., 53, 6835-6875, https://doi.org/10.1007/s00382019-04958-z.

Barnhart, T. B., N. P. Molotch, B. Livneh, A. A. Harpold, J. F. Knowles, and D. Schneider, 2016: Snowmelt rate dictates streamflow. Geophys. Res. Lett., 43, 8006-8016, https://doi.org/ 10.1002/2016GL069690.

Baxter, M. A., C. E. Graves, and J. T. Moore, 2005: A climatology of snow-to-liquid ratio for the contiguous United States. Wea. Forecasting, 20, 729-744, https://doi.org/10.1175/WAF856.1.

Cherkauer, K. A., and D. P. Lettenmaier, 1999: Hydrologic effects of frozen soils in the upper Mississippi River basin. J. Geophys. Res., 104, 19599-19610, https://doi.org/10.1029/1999JD900337.

Christian, J., K. Christian, and J. B. Basara, 2015: Drought and pluvial dipole events within the Great Plains of the United States. J. Appl. Meteor. Climatol., 54, 1886-1898, https:// doi.org/10.1175/JAMC-D-15-0002.1.

Cook, K. H., E. K. Vizy, Z. S. Launer, and C. M. Patricola, 2008: Springtime intensification of the Great Plains low-level jet and Midwest precipitation in GCM simulations of the twenty-first century. J. Climate, 21, 6321-6340, https://doi.org/10.1175/ 2008JCLI2355.1.

Daly, C., W. P. Gibson, G. H. Taylor, M. K. Doggett, and J. I. Smith, 2007: Observer bias in daily precipitation measurements at U.S. Cooperative Network stations. Bull. Amer. Meteor. Soc., 88, 899-912, https://doi.org/10.1175/BAMS-88-6-899.

Davis, R. S., 2001: Flash flood forecast and detection methods. Severe Convective Storms, Meteor. Monogr., No. 50, Amer. Meteor. Soc., 481-525.

DeAngelis, A., F. Dominguez, Y. Fan, A. Robock, M. D. Kustu, and D. Robinson, 2010: Evidence of enhanced precipitation due to irrigation over the Great Plains of the United States. J. Geophys. Res., 115, D15115, https://doi.org/10.1029/ 2010JD013892.

DeGaetano, A. T., 2009: Time-dependent changes in extremeprecipitation return-period amounts in the continental United States. J. Appl. Meteor. Climatol., 48, 2086-2099, https://doi.org/ 10.1175/2009JAMC2179.1.

Doubler, D. L., J. A. Winkler, X. Bian, C. K. Walters, and S. Zhong, 2015: An NARR-derived climatology of southerly and northerly low-level jets over North America and coastal environs. J. Appl. Meteor. Climatol., 54, 1596-1619, https:// doi.org/10.1175/JAMC-D-14-0311.1.

Downton, M. W., J. Z. B. Miller, and R. A. Pielke Jr., 2005: Reanalysis of US National Weather Service flood loss database. Nat. Hazards Rev., 6, 13-22, https://doi.org/10.1061/ (ASCE)1527-6988(2005)6:1(13).

Easterling, D. R., and Coauthors, 2017: Precipitation change in the United States. Climate Science Special Report: Fourth National Climate Assessment, D. J. Wuebbles et al., Eds.,
Vol. I, U.S. Global Change Research Program, 207-230, https://doi.org/10.7930/J0H993CC.

Ettema, R., and L. Zabilansky, 2004: Ice influences on channel stability: Insights from Missouri's fort peck reach. J. Hydraul. Eng, 130, 279-292, https://doi.org/10.1061/(ASCE)0733-9429(2004) 130:4(279).

Feng, Z., L.-Y. Leung, S. Hagos, R. A. Houze Jr., C. Burleyson, and K. Balaguru, 2016: More frequent intense and long-lived storms dominate the springtime trend in central U.S. rainfall. Nat. Commun., 7, 13429, https://doi.org/10.1038/ncomms13429.

Findell, K. L., and E. A. Eltahir, 2003a: Atmospheric controls on soil moisture-boundary layer interactions: Three-dimensional wind effects. J. Geophys. Res., 108, 8385, https://doi.org/ 10.1029/2001JD001515.

, and,$- 2003 \mathrm{~b}$ : Atmospheric controls on soil moistureboundary layer interactions. Part II: Feedbacks within the continental United States. J. Hydrometeor., 4, 570-583, https://doi.org/10.1175/1525-7541(2003)004<0570:ACOSML> 2.0.CO;2.

Flanagan, P. X., J. B. Basara, and X. Xiao, 2017: Long-term analysis of the asynchronicity between temperature and precipitation maxima in the United States Great Plains. Int. J. Climatol., 37, 3919-3933, https://doi.org/10.1002/joc.4966.

- — - J. Furtado, and X. Xiao, 2018: Primary atmospheric drivers of pluvial years in the United States Great Plains. J. Hydrometeor., 19, 643-658, https://doi.org/10.1175/JHM-D17-0148.1.

— - and Coauthors, 2020: A hydrometeorological assessment of the historic 2019 flood of Nebraska, Iowa, and South Dakota. Bull. Amer. Meteor. Soc., 101, E817-E829, https://doi.org/ 10.1175/BAMS-D-19-0101.1.

Frei, C., C. Schär, D. Lüthi, and H. C. Davies, 1998: Heavy precipitation processes in a warmer climate. Geophys. Res. Lett., 25, 1431-1434, https://doi.org/10.1029/98GL51099.

Freudiger, D., I. Kohn, K. Stahl, and M. Weiler, 2014: Large-scale analysis of changing frequencies of rain-on-snow events with flood-generation potential. Hydrol. Earth Syst. Sci., 18, 2695-2709, https://doi.org/10.5194/hess-18-2695-2014.

Fritsch, J. M., R. J. Kane, and C. R. Chelius, 1986: The contribution of mesoscale convective weather systems to the warm-season precipitation in the United States. J. Climate Appl. Meteor., 25, 1333-1345, https://doi.org/10.1175/1520-0450(1986)025<1333: TCOMCW $>2.0 . \mathrm{CO} ; 2$.

Gimeno, L., A. Drumond, R. Nieto, R. M. Trigo, and A. Stohl, 2010: On the origin of continental precipitation. Geophys. Res. Lett., 37, L13804, https://doi.org/10.1029/2010GL043712.

—, R. Nieto, A. Drumond, R. Castillo, and R. Trigo, 2013: Influence of the intensification of the major oceanic moisture sources on continental precipitation. Geophys. Res. Lett., 40, 1443-1450, https://doi.org/10.1002/grl.50338.

Groisman, P. Ya., R. W. Knight, T. R. Karl, D. R. Easterling, B. Sun, and J. H. Lawrimore, 2004: Contemporary changes of the hydrological cycle over the contiguous United States: Trends derived from in situ observations. J. Hydrometeor., 5, 64-85, https://doi.org/10.1175/1525-7541(2004)005<0064: CCOTHC $>2.0 . \mathrm{CO} ; 2$.

, — - D. R. Easterling, T. R. Karl, G. C. Hegerl, and V. N. Razuvaev, 2005: Trends in intense precipitation in the climate record. J. Climate, 18, 1326-1350, https://doi.org/10.1175/ JCLI3339.1.

- — - and T. R. Karl, 2012: Changes in intense precipitation over the central United States. J. Hydrometeor., 13, 47-66, https://doi.org/10.1175/JHM-D-11-039.1. 
Higgins, R. W., Y. Yao, E. S. Yarosh, J. E. Janowiak, and K. C. Mo, 1997: Influence of the Great Plains low-level jet on summertime precipitation and moisture transport over the central United States. J. Climate, 10, 481-507, https://doi.org/10.1175/ 1520-0442(1997)010<0481:IOTGPL>2.0.CO;2.

Howarth, M. E., D. C. Thorncroft, and L. F. Bosart, 2019: Changes in extreme precipitation in the northeast United States: 19792014. J. Hydrometeor., 20, 673-689, https://doi.org/10.1175/ JHM-D-18-0155.1.

$\mathrm{Hu}, \mathrm{Z}$., and B. Huang, 2009: Interferential impact of ENSO and PDO on dry and wet conditions in the U.S. Great Plains. J. Climate, 22, 6047-6065, https://doi.org/10.1175/2009JCLI2798.1.

Janssen, E., D. J. Wuebbles, K. E. Kunkel, S. C. Olsen, and A. Goodman, 2014: Observational- and model-based trends and projections of extreme precipitation over the contiguous United States. Earth's Future, 2, 99-113, https://doi.org/ 10.1002/2013EF000185.

Karl, T. R., and R. W. Knight, 1998: Secular trends of precipitation amount, frequency, and intensity in the United States. Bull. Amer. Meteor. Soc., 79, 231-241, https://doi.org/10.1175/15200477(1998)079<0231:STOPAF>2.0.CO;2.

_- J. M. Melilo, and T. C. Peterson, Eds., 2009: Global Climate Change Impacts in the United States. Cambridge University Press, 188 pp., http://downloads.globalchange.gov/usimpacts/ pdfs/climate-impacts-report.pdf.

Kendall, M. G., 1975: Rank Correlation Methods. Griffin, 202 pp.

Kozdrój, J., and J. D. van Elsas, 2000: Response of the bacterial community to root exudates in soil polluted with heavy metals assessed by molecular and cultural approaches. Soil Biol. Biochem., 32, 1405-1417, https://doi.org/10.1016/S00380717(00)00058-4.

Kunkel, K. E., 2003: North American trends in extreme precipitation. Nat. Hazards, 29, 291-305, https://doi.org/10.1023/ A:1023694115864.

—, K. Andsager, and D. R. Easterling, 1999: Long-term trends in extreme precipitation events over the conterminous United States and Canada. J. Climate, 12, 2515-2527, https://doi.org/ 10.1175/1520-0442(1999)012<2515:LTTIEP > 2.0.CO;2.

Lanicci, J. M., and T. T. Warner, 1991a: A synoptic climatology of the elevated mixed-layer inversion over the southern Great Plains in spring. Part I: Structure, dynamics, and seasonal evolution. Wea. Forecasting, 6, 181-197, https://doi.org/10.1175/ 1520-0434(1991)006<0181:ASCOTE >2.0.CO;2.

— layer inversion over the southern Great Plains in spring. Part II: The life cycle of the lid. Wea. Forecasting, 6, 198-213, https:// doi.org/10.1175/1520-0434(1991)006<0198:ASCOTE >2.0.CO;2.

Mallakpour, I., and G. Villarini, 2015: The changing nature of flooding across the central United States. Nat. Climate Change, 5, 250-254, https://doi.org/10.1038/nclimate2516.

Mann, H. B., 1945: Nonparametric tests against trend. Econometrica, 13, 245-259, https://doi.org/10.2307/1907187.

Maurer, E. P., and D. P. Lettenmaier, 2004: Potential effects of long-lead hydrologic predictability on Missouri River main-stem reservoirs. J. Climate, 17, 174-186, https://doi.org/10.1175/ 1520-0442(2004)017<0174:PEOLHP $>2.0$.CO;2.

McCabe, G. J., M. P. Clark, and L. E. Hay, 2007: Rain-on-snow events in the western United States. Bull. Amer. Meteor. Soc., 88, 319-328, https://doi.org/10.1175/BAMS-88-3-319.

Mei, R., and G. Wang, 2011: Impact of sea surface temperature and soil moisture on summer precipitation in the United States based on observational data. J. Hydrometeor., 12, 1086-1099, https://doi.org/10.1175/2011JHM1312.1.
Mo, K. C., and R. W. Higgins, 1996: Large-scale atmospheric moisture transport as evaluated in the NCEP/NCAR and the NASA/DAO reanalyses. J. Climate, 9, 1531-1545, https://doi.org/10.1175/1520-0442(1996)009<1531:LSAMTA > 2.0.CO;2.

Monaghan, A. J., D. L. Rife, J. O. Pinto, C. A. Davis, and J. R. Hannan, 2010: Global precipitation extremes associated with diurnally varying low-level jets. J. Climate, 23, 5065-5084, https://oi.org/10.1175/2010JCLI3515.1.

Moore, B. J., D. Keyser, and L. F. Bosart, 2019: Linkages between extreme precipitation events in the central and eastern United States and Rossby wave breaking. Mon. Wea. Rev., 147, 3327-3349, https://doi.org/10.1175/MWRD-19-0047.1.

Najibi, N., N. Devineni, and M. Lu, 2017: Hydroclimate drivers and atmospheric teleconnections of long duration floods: An application to large reservoirs in the Missouri River basin. Adv. Water Resour., 100, 153-167, https://doi.org/10.1016/ j.advwatres.2016.12.004.

NCDC, 2020: Climate at a glance. NOAA, accessed 5 October 2020, https://www.ncdc.noaa.gov/cag/.

Niu, G.-Y., and Z.-L. Yang, 2006: Effects of frozen soil on snowmelt runoff and soil water storage at a continental scale. J. Hydrometeor., 7, 937-952, https://doi.org/10.1175/ JHM538.1.

Noguchi, S., N. Abdul Rahim, Y. Zulkifli, M. Tani, and T. Sammori, 1997: Rainfall-runoff responses and roles of soil moisture variations to the response in tropical rain forest, Bukit Tarek, Malaysia. J. For. Res., 2, 125-132, https://doi.org/10.1007/ BF02348209.

Pei, L., N. Moore, S. Zhong, A. D. Kendall, Z. Gao, and D. W. Hyndman, 2016: Effects of irrigation on summer precipitation over the United States. J. Climate, 29, 3541-3558, https://doi.org/ 10.1175/JCLI-D-15-0337.1.

Pryor, S. C., J. A. Howe, and K. E. Kunkel, 2009: How spatially coherent and statistically robust are temporal changes in extreme precipitation in the contiguous USA? Int. J. Climatol., 29, 31-45, https://doi.org/10.1002/joc.1696.

Qiao, L., Z. Pan, R. B. Herrmann, and Y. Hong, 2014: Hydrological variability and uncertainty of lower Missouri River basin under changing climate. J. Amer. Water Resour. Assoc., 50, 246-260, https://doi.org/10.1111/jawr.12126.

Reif, D. W., and H. B. Bluestein, 2017: A 20-year climatology of nocturnal convection initiation over the central and southern Great Plains during the warm season. Mon. Wea. Rev., 145, 1615-1639, https://doi.org/10.1175/MWR-D-16-0340.1.

Ribeiro, B. Z., and L. F. Bosart, 2018: Elevated mixed layers and associated severe thunderstorm environments in South and North America. Mon. Wea. Rev., 146, 3-28, https://doi.org/ 10.1175/MWR-D-17-0121.1.

Rosenzweig, C., F. N. Tubiello, R. Goldberg, E. Mills, and J. Bloomfield, 2002: Increased crop damage in the US from excess precipitation under climate change. Global Environ. Change, 12, 197-202, https://doi.org/10.1016/S0959-3780(02) 00008-0.

Rozalis, S., E. Morin, Y. Yair, and C. Price, 2010: Flash flood prediction using an uncalibrated hydrological model and radar rainfall data in a Mediterranean watershed under changing hydrological conditions. J. Hydrol., 394, 245-255, https://doi.org/ 10.1016/j.jhydrol.2010.03.021.

Ruiz-Barradas, A., and S. Nigam, 2005: Warm-season rainfall variability over the U.S. Great Plains in observations, NCEP and ERA-40 reanalyses, and NCAR and NASA atmospheric 
model simulations. J. Climate, 18, 1808-1830, https://doi.org/ 10.1175/JCLI3343.1.

Tuttle, J. D., and C. A. Davis, 2006: Corridors of warm season precipitation in the central United States. Mon. Wea. Rev., 134, 2297-2317, https://doi.org/10.1175/MWR3188.1.

USDA, 2019: Farmers prevented from planting crops on more than 19 million acres. Farm Service Agency, accessed 30 June 2020, https://www.fsa.usda.gov/news-room/news-releases/2019/reportfarmers-prevented-from-planting-crops-on-more-than-19million-acres.

U.S. Department of the Interior Bureau of Reclamation, 2016: Missouri River basin. Reclamation: Managing water in the West, Bureau of Reclamation Rep., 6-1-6-25, https://www.usbr.gov/ climate/secure/docs/2016secure/2016SECUREReport-chapter6.pdf.

USGS and NOAA, 1972: The Black Hills-Rapid City flood of June 9-10, 1972: A description of the storm and flood. Geological Survey Professional Paper 877, 58 pp., https://pubs.usgs.gov/ pp/0877/report.pdf.

_ 1977: Floods in Kansas City, Missouri and Kansas, September 12-13, 1977. Geological Survey Professional Paper 1169, 56 pp., https://pubs.usgs.gov/pp/1169/report.pdf.

Wallace, J. M., 1975: Diurnal variations in precipitation and thunderstorm frequency over the conterminous United States. Mon. Wea. Rev., 103, 406-419, https://doi.org/10.1175/15200493(1975)103<0406:DVIPAT>2.0.CO;2.

Weaver, S., S. Baxter, and K. Harnos, 2016: Regional changes in the interannual variability of warm season precipitation. J. Climate, 29, 5157-5173, https://doi.org/10.1175/JCLI-D-14-00803.1.
Wilcox, R. R., 2001: Fundamentals of Modern Statistical Methods. Springer-Verlag, $258 \mathrm{pp}$.

Wimhurst, J. J., and J. S. Greene, 2020: The influence of climate change on low-level jet characteristics over the south-central plains as simulated by CMIP5 models. Int. J. Climatol., 40, 6020-6038, https://doi.org/10.1002/joc.6563.

Wise, E. K., C. A. Woodhouse, G. J. McCabe, G. T. Pederson, and J.-M. St.-Jacques, 2018: Hydroclimatology of the Missouri River basin. J. Hydrol., 19, 161-182, https://doi.org/10.1175/ JHM-D-17-0155.1.

Xiao, Y., J. Wan, and G. J. D. Hewings, 2013: Flooding and the Midwest economy: Assessing the Midwest floods of 1993 and 2008. GeoJournal, 78, 245-258, https://doi.org/10.1007/ s10708-011-9415-9.

Yang, L., B. K. Wylie, L. L. Tieszen, and B. C. Reed, 1998: An analysis of relationships among climate forcing and timeintegrated NDVI of grasslands over the U.S. northern and central Great Plains. Remote Sens. Environ., 65, 25-37, https:// doi.org/10.1016/S0034-4257(98)00012-1.

Yu, L., S. Zhong, L. Pei, X. Bian, and W. E. Heilman, 2016: Contribution of large-scale circulation anomalies to changes in extreme precipitation frequency in the United States. Environ. Res. Lett., 11, 044003, https://doi.org/10.1088/17489326/11/4/044003.

Zhao, S., Y. Deng, and R. Black, 2017: A dynamical and statistical characterization of U.S. extreme precipitation events and their associated large-scale meteorological patterns. J. Climate, 30, 1307-1326, https://doi.org/10.1175/JCLI-D-15-0910.1. 